\title{
LAS FALENCIAS DEL TEST DE INTERÉS PÚBLICO COMO INSTRUMENTO DE PONDERACIÓN ENTRE EL ACCESO A LA INFORMACIÓN PÚBLICA

\author{
Y LA VIDA PRIVADA
}

["The Flaws of the Public Interest Test as a Weighting Instrument Between the Access to Public Information and Private Life"]

\author{
Ignacio Covarrubias Cuevas* \\ Universidad del Desarrollo, Santiago, Chile
}

\begin{abstract}
RESUMEN
El trabajo problematiza la procedencia y el empleo del test de interés público por parte del Consejo para la Transparencia, a propósito de la ponderación entre el derecho de acceso a la información y el derecho a la vida privada, en la perspectiva de la coherencia interna de la jurisprudencia administrativa de ese Consejo y en relación con el principio de proporcionalidad o con una de sus exigencias cuando se encuentra en juego el derecho a la intimidad. Asimismo, se destaca la omisión del Consejo en aplicar el aludido test cuando se está frente a "datos sensibles", por lo que se propone un reforzamiento del sustrato
\end{abstract}

\begin{abstract}
This work inquires into the origin and use of the public interest test by the Council for Transparency in relation to the weighing between the right of access to information and the right to private life from the standpoint of the internal coherence of the administrative jurisprudence of this Council and in relation to the principle of proportionality or with one of its demands when the right to privacy is at stake. Likewise, it highlights the omission incurred by the Council in applying the aforementioned test when facing "sensitive data"; consequently, it proposes strengthening the underlying
\end{abstract}

* Doctor en Derecho por la Universidad de los Andes, profesor de Derecho constitucional y director del Centro de Justicia Constitucional de la Universidad del Desarrollo. Correo postal: Facultad de Derecho, Universidad del Desarrollo, Av. Plaza 680, San Carlos de Apoquindo, Las Condes, Santiago. Correo electrónico: icovarrubias@ udd. Este artículo forma parte del Proyecto de Investigación financiado por la Dirección de Investigación de la referida casa de estudios, titulado "El principio de proporcionalidad en la jurisprudencia constitucional chilena" y que se encuentra en etapa de finalización. 
normativo tanto constitucional como legal del principio de divisibilidad, que no padece las falencias que presenta el test de interés público y es un instrumento que permite satisfacer la transparencia de la función pública (derecho de acceso a la información) y el pleno respeto al contenido medular de los derechos fundamentales (los "datos sensibles").

Palabras Clave

Transparencia - Test de interés público - Derecho a la intimidad constitutional and legal regulatory framework of the principle of divisibility, which does not have the flaws of the public interest test and is an instrument that allows meeting transparency in public administration (right of access to information) and full compliance of the core content of the fundamental rights (the "sensitive data").

KeYWORDS

Transparency - Public interest test Right to privacy

ReCibido el 26 de marzo y ACEPTAdo el 22 de mayo de 2012.

\section{ESTRUCTURA Y OBJETO}

En su primera parte, el presente trabajo persigue efectuar un recuento primordialmente descriptivo de las normas jurídicas que enmarcan la relación de lo público y lo privado en la Ley No 20.285: Sobre acceso a la información pública, comúnmente denominada "Ley de transparencia" (modalidad esta que se utilizará en el presente trabajo), para luego indicar el modo en que el Consejo para la Transparencia ha aplicado el test de interés público, uno de los instrumentos que ha concebido para delimitar la transparencia pública (y el derecho de acceso a la información) con el derecho a la vida privada.

En una segunda parte más bien analítica este artículo pretende contribuir a dar respuesta a varias interrogantes que dicen relación con el empleo del test de interés público por el Consejo para la Transparencia (en adelante, el "CT" o el Consejo). La primera pregunta es si el referido test posee sustento normativo en la "Ley de transparencia". La respuesta será negativa, a la luz del texto, contexto e historia fidedigna del establecimiento de dicho cuerpo legal. La segunda interrogante se vincula con la coherencia exhibida por el Consejo al momento de aplicar el señalado test del modo en que el mismo organismo lo ha formulado. El tercer aspecto abordado procura contestar si el referido criterio jurisprudencial ha prestado un buen servicio a la relación existente entre la transparencia pública y el derecho a la vida privada, manifestado fundamentalmente en su modalidad de "datos sensibles". Aquí se critica de manera particular el empleo de la regla de la proporcionalidad en sentido estricto como método de adjudicación entre derechos, como la intimidad, y bienes públicos, como la transparencia.

La parte final, derechamente propositiva, lleva a cabo un esfuerzo por 
revelar el sustento normativo que, desde una perspectiva constitucional y legal, otorgue un mayor impulso y perspectiva al principio de divisibilidad, un instrumento que la "Ley de transparencia" prevé, que no carga con los falencias de origen como de estructura de "test de daño"y cuya adecuada aplicación en clave constitucional permite conciliar la satisfacción del interés público, vía ejercicio del derecho de acceso, con pleno respeto a los derechos fundamentales y, en particular, con el derecho a una de las coberturas más íntimas del derecho a la vida privada.

Por último, en el ámbito metodológico sólo cabe añadir que el objeto de este artículo es más bien analítico desde el punto de vista conceptual que un análisis preferencialmente jurisprudencial de las decisiones del CT. Si bien se han tenido muchos casos a la vista, ello en modo alguno conlleva la pretensión de presentar un trabajode análisis jurisprudencial, por lo que en muchas ocasiones las decisiones del Consejo son exhibidas a modo meramente referencial, sin un afán exhaustivo,ya sea para sustentar una crítica o ir en apoyo de la perspectiva conceptual que se sostiene.

\section{LO PÚBLICO Y LO PRIVADO \\ SEGÚN EL MARCO NORMATIVO CONSTITUCIONAL Y LEGAL}

La Ley $\mathrm{N}^{\circ}$ 20.285: sobre Acceso a la información pública fue aprobada como consecuencia de la reforma constitucional que incorporó al artículo 8 C.Pol. el principio de publicidad de "los actos y resoluciones de los órganos del Estado", contemplando entre otras limitaciones a dicho propósito, "los derechos de las personas" . De conformidad con la indicada disposición constitucional, el aludido texto legal, junto con desarrollar las denominadas salvedades a la publicidad y prever el modo en que los distintos órganos del Estado deben cumplir con el deber de transparencia activa, regula el derecho de acceso a la información que se encuentra en poder de la Administración ${ }^{2}$.

${ }^{1}$ Constitución Politica de la República, Ley No 20.050 que fija el texto refundido de la misma, Diario Oficial 22 de septiembre de 2005. Su artículo 8 inciso $2^{\circ}$, prescribe: "Son públicos los actos y resoluciones de los órganos del Estado, así como sus fundamentos $y$ los procedimientos que utilicen". El inciso siguiente dispone las excepciones a dicho principio de publicidad, agrega que "sólo una ley de quórum calificado podrá establecer la reserva o secreto de aquéllos -actos y resoluciones- o de éstos -fundamentos y procedimientos-, cuando la publicidad afectare el debido cumplimiento de las funciones de dichos órganos, los derechos de las personas, la seguridad de la Nación o el interés nacional.".

${ }^{2}$ La Ley No 20.285, sobre Acceso a la información pública, Diario Oficial de 20 de agosto de 2008. Su art. $10^{\circ}$ establece que toda persona puede "solicitar y recibir información de cualquier órgano de la Administración [...] contenidas en actos, resoluciones, actas, expedientes, contratos, acuerdos, asi como toda información elaborada con presupuesto público, cualquiera 
Al mismo tiempo, la referida ley creó el Consejo para la Transparencia, organismo al que dotó de potestades para "[ $\mathrm{r}$ ]esolver los reclamospor denegación de acceso a la información" como para "velarpor la debida reserva de los datos e informaciones que [...] tengan carácter secreto o reservado" $\mathrm{e}$, igualmente, para "velar por el adecuado cumplimiento de la ley $N^{\circ} 19.628$ de protección de datos de carácter personal, por parte de los órganos de la Administración", entre otras atribuciones.

Así, para la Constitución Política y la "Ley de transparencia" (en adelante la "Ley"), lo público, en la perspectiva del principio de transparencia de los órganos de la Administración del Estado, se encuentra configurado por "los actos y resoluciones de los órganos del Estado así como sus fundamentos y los procedimientos que utilicen", y también por "los documentos que les sirvan de sustento o complemento directo y esencial". Del mismo modo, la "Ley" establece que "es pública la información elaborada con presupuesto público y toda otra información que obre en poder de los órganos de la Administración, cualquiera sea su formato, soporte, fecha de creación, origen, clasificación o procesamiento".

En el específico ámbito del ejercicio del derecho de acceso a la información de los Órganos de la Administración del Estado, a requerimiento de cualquier persona (transparencia pasiva), la "Ley" asegura dicho acceso " $a$ las informaciones contenidas en actos, resoluciones, actas, expedientes, contratos y acuerdos, asi como a toda información elaborada con presupuesto público, cualquiera sea el formato o soporte en que se contenga".

En cuanto a aquella información que los Órganos de la Administración deben "mantener a disposición permanente del público, a través de sus sitios electrónicos" ${ }^{\prime 10}$, sin necesidad de solicitud previa (transparencia activa), la "Ley" establece un listado de antecedentes, entre los cuales cabe destacar, a modo meramente ejemplar, "las correspondientes remuneraciones"11 del

sea el formato o soporte en que se contenga". El artículo $5^{\circ}$, inciso segundo, añade que "es pública [...] toda otra información que obre en poder de los órganos de la Administración, cualquiera sea su formato, soporte, fecha de creación, origen, clasificación o procesamiento, a menos que esté sujeta a las excepciones señaladas".

${ }^{3}$ Ibíd., artículo 33, b).

${ }^{4}$ Ibíd., artículo 33, J).

${ }^{5}$ Ibíd., artículo 33, m).

${ }^{6}$ Artículo 8 C.Pol.

${ }^{7}$ Ley $\mathrm{N}^{\circ}$ 20.285, sobre: Acceso a la información pública, Diario Oficial de 20 de agosto de 2008 , artículo 5 inciso $1^{\circ}$.

${ }^{8}$ Ibíd., artículo 5 inciso $2^{\circ}$.

${ }^{9}$ Ibíd., artículo 10,inciso $2^{\circ}$.

${ }^{10}$ Ibíd., artículo 7.

${ }^{11}$ Ibíd., artículo 7 letra d). 
personal de planta, a contrata y a honorarios, "todo aporte económico entregado a personas jurídicas o naturales" 12 y, "las nóminas de beneficiarios de los programas sociales en ejecución" "13, además de otra especie de información que debe indicarse, tal como la estructura orgánica y el marco normativo de la entidad obligada a mantenerla a disposición de las personas.

Por otra parte, lo "privado", según la formulación constitucional y legal, dice relación con aquella información que los Órganos de la Administración del Estado no están obligados a mantener a disposición del público -bajo la transparencia activa- ni a revelar con ocasión del ejercicio del derecho de acceso - transparencia pasiva- por tratarse de información que se encuentra protegida por los derechos fundamentales. Así lo establece expresamente la Constitución al prever como una de las causales de reserva o secreto a "los derechos de las personas".

La "Ley" reconoció explícitamente a aquéllas "su seguridad, su salud, la esfera de su vida privada o derechos de carácter comercial o económico" 14 como aquellos derechos fundamentales que constituyen límites al principio de publicidad de los órganos del Estado, sea ésta manifestada como transparencia activa de la Administración o como derecho de los particulares de acceder a la información pública. Así, en materia de transparencia de los órganos de la Administración, tanto para la Constitución Politica como para la "Ley", lo privado para las personas no es sólo lo intimo, como pudiera pensarse en estricto sentido, sino también toda otra información cuya revelación pública pudiera comprometer "los derechos de laspersonas", en general y "su seguridad, su salud [...] o derechos de carácter comercial o económico", además de "la esfera de su vida privada"15.

\section{LO PÚBLICO Y LO PRIVADO SEGÚN EL CONSEJO PARA LA TRANSPARENCIA:}

EL TEST DE INTERÉS PÚBLICO COMO INSTRUMENTO DE DELIMITACIÓN ENTRE EL DERECHO DE ACCESO Y LA INTIMIDAD

El Consejo se ha valido de diversos instrumentos para ir delineando las fronteras entre lo público y lo privado, a saber, la delimitación entre el derecho

${ }^{12}$ Ibíd., artículo 7 letra f).

${ }^{13}$ Ibíd., artículo 7 letra I).

${ }^{14}$ Ibíd., artículo $21 \mathrm{~N}^{\circ} 2$, que reconoce la siguiente causal de secreto o reserva: "Cuando su publicidad, comunicación o conocimiento afecte los derechos de las personas, particularmente tratándose de su seguridad, su salud, la esfera de su vida privada o derechos de carácter comercial o económico."

${ }^{15}$ Ibíd. (por todas). 
de acceso y otros derechos fundamentales. Ha acudido al test de daño ${ }^{16}$, a la figura pública devaluada en su intimidad ${ }^{17}$, a los "datos sensibles" como barrera infranqueable al derecho de acceso ${ }^{18} \mathrm{y}$, al test de interés público ${ }^{19}$, entre otros criterios de adjudicación e interpretación. Este último se ha ido perfilando como una de las herramientas centrales empleadas por el CT para los efectos de determinar si la información solicitada, en los casos que comprometa a los derechos de las personas, ha de ser o no públicamente revelada.

El test de interés público consiste en un proceso de ponderación entre el beneficio que reporta el dar a conocer la información solicitada versus el daño que su divulgación generaría en los derechos de las personas. (Si el perjuicio se predica de bienes públicos, como la seguridad o el interés nacional, la operación pasa a llamarse test de daño). Se denomina test de interés público porque se asume que sólo un interés público predominante justifica traspasar aquella barrera que impide revelar información que se encuentra protegida por los derechos fundamentales. De este modo lo ha entendido desde un principio el $\mathrm{CT}^{20}$. Igualmente, este organismo ha sostenido que el test de interés público (también el test de daño) es una aplicación del principio de

\footnotetext{
${ }^{16}$ Se ha entendido por el "test de daño" la realización de un balance "entre el interés de retener la información y el interés de divulgarla para determinar si el beneficio público resultante de conocer la información solicitada es mayor que el daño que podría causar su revelación" (a partir de la decisión A45-09, c. $8^{\circ}$ ). Suele aplicarse en los casos en que el interés comprometido es predominantemente público ("el debido cumplimiento de las funciones del órgano" "la seguridad de la Nación”, y "el interés nacional”, en el caso de los números 1,3 y 4 del artículo 21 de la "Ley de transparencia”).

${ }^{17}$ Así, se ha afirmado que los "funcionarios públicos, poseen una esfera de vida privada más delimitada en virtud precisamente de la función que ejercen" (a modo ejemplar, en la decisión A47-09, c. 18 ${ }^{\circ}$ ).

${ }^{18}$ El CT ha dicho que tal información "se enmarca dentro de lo que La Ley de Protección de Datos Personales define como datos sensibles, toda vez que [en tal caso] se refiere a un determinado estado de salud físico o psíquico de las personas sobre las que se consulta ( por ejemplo, la decisión C198-10, c. $9^{\circ}$ ).

${ }^{19} \mathrm{El}$ "test de interés público" (invocado desde la decisión A115-09) es similar al "test de daño"en cuanto supone un idéntico proceso de balanceo, aunque el primer estándar tiene lugar sólo en los casos en que los bienes afectados con la revelación pública son "los derechos de las personas" (como lo indica el número 2 del artículo 21 de la "Ley de transparencia").

${ }^{20}$ CT, Decisión A115-09, c. 9०: “[...] conviene considerar que cuando la transparencia puede exponer la vida privada o el patrimonio de las personas, la doctrina y la legislación comparada entienden que en principio existe una barrera que restringe la divulgación de los documentos que contienen esta información. Pese a ello '...pueden existir circunstancias excepcionales en que el interés público justifique su divulgación. Estas circunstancias excepcionales suponen una difícil y compleja valoración de los intereses en juego".
} 
proporcionalidad. Así lo ha dicho: "Establecido que estamos en presencia de un derecho de rango constitucional la reserva o secreto pasa a limitarlo o restringirlo, por lo que debe respetar el principio de proporcionalidad que supone analizar, conforme señala la doctrina: a) si la medida es eficaz, b) si no existe un medio más moderado para la consecución eficaz del propósito buscado (en este caso, cautelar el secreto) y, por último, c) si de la medida a adoptar (en este caso, el secreto absoluto) derivan más beneficios o ventajas para el interés general que perjuicios sobre otros bienes o valores en conflicto (véase Bernal P., Carlos. El principio de proporcionalidad y los derechos fundamentales, $2^{a} \mathrm{ed}$. Madrid: Centro de Estudios Politicos y Constitucionales, 2005, y Garcia P., Gonzalo y Contreras V., Pablo. Derecho de Acceso a la Información en Chile: Nueva Regulación e Implicancias para el Sector de la Defensa Nacional. /en/ Estudios Constitucionales año 7, $N^{\circ}$ 1, 2009, p. 144)"21.

Complementando lo señalado, el CT ha expresado que el test de interés público persigue "ponderar si el interés público a obtener con la entrega de información justifica su divulgación y vence [...] la reserva" 22 . Por otra parte, $\mathrm{y}$ a mayor abundamiento, el Consejo alude, en la decisión precedentemente citada, a una sentencia del Tribunal Constitucional que se refiere al test de proporcionalidad: "En términos semejantes nuestro Tribunal Constitucional ha dicho sobre este principio lo siguiente: 'Reiterando nuestra jurisprudencia constitucional anterior (Sentencia rol $N^{\circ} 226$, Considerando 47, y Sentencia rol $N^{\circ} 280$, Considerando 29), una limitación a un derecho fundamental es justificable, cuando dicho mecanismo es el estrictamente necesario o conveniente para lograr un objetivo constitucionalmente válido, debiendo consecuentemente el legislador elegir aquellas limitaciones que impliquen gravar en menor forma los derechos fundamentales" (Sentencia rol N ${ }^{\circ}$ 519/2006, de 5 de junio de 2007, consid. 19 $)^{\circ}{ }^{\prime 23}$.

Rajevic anota que este procedimiento -refiriéndose al test de interés público como también al test de daño- contribuye a determinar "cuando se dará preferencia a la transparencia y cuando prevalecerán el debido cumplimiento de las funciones del órgano, los derechos de terceros, el interés nacional y la seguridad de la nación" ${ }^{24}$, añadiendo que "faltan más decisiones para ir arribando a criterios sustantivos" 25 . Sobre algunos criterios nos referiremos enseguida, para posteriormente efectuar un examen entre lo

${ }^{21}$ CT, Decisión A45-09, c. 10º replicada en A 115-09, c. $9^{\circ}$ y C402-09, c. 13, entre otras.

${ }^{22}$ CT, Decisión C193-10, c. $6^{\circ}$.

${ }^{23}$ Ibíd.

${ }^{24}$ Rajevic Mosler, Enrique, La jurisprudencia inicial del Consejo para la Transparencia, en Revista de Derecho del Consejo de Defensa del Estado, 22 (2009), p. 46.

${ }^{25}$ Ibíd., p. 47. 
prometido por el test y lo resuelto por el CT en materia de interés público y derecho a la intimidad.

\section{Algunos Criterios adoptados por el Consejo para la TRANSPARENCIA AL APLICAR EL TEST DE INTERÉS PÚBLICO ENTRE EL DERECHO DE ACCESO Y EL DERECHO A LA INTIMIDAD}

Sin procurar ser completamente exhaustivos en el recuento de las decisiones del Consejo, procuraremos sintetizar una muestra suficiente de casos resueltos por él para los efectos de exhibir una cierta "doctrina” o, al menos, una "línea" jurisprudencial administrativa sobre la materia.

Como señalábamos, en las ocasiones en que el Consejo ha arribado a la conclusión de que no obstante existir una información protegida por el derecho a la vida privada, ésta debe ser igualmente revelada por concurrir un "interés público prevaleciente", lo ha hecho utilizando el denominado test de interés público en cuya virtud se lleva a cabo "[...] un balance entre el interés de retener la información y el interés de divulgarla para determinar si el beneficio público resultante de conocer la información solicitada es mayor que el daño que podría conocer su revelación" 26.

No son muchas las ocasiones en que el Consejo ha utilizado el aludido método ponderativo formalmente ${ }^{27}$ con relación al derecho a la vida privada. Su baja aplicación comparativa se debe en alguna medida a que en aquellos casos en que pudo haberse aplicado el referido test, éste no pudo finalmente operar por no haber existido oposición de un tercero, lo cual impidió, a juicio del Consejo, "verificar el daño que este sufriría de entregarse la información y

${ }^{26}$ CT, Decisión A45-09, c $8^{\circ}$ y ss. Si bien en ésta se utilizó el "test de daño" (información pública versus el debido cumplimiento de las funciones del organismo, la Seguridad de la Nación y de las personas) igualmente formuló una noción aplicable a ambos test. Empero, cabe precisar que de modo coetáneo a este test, ya había hecho su debut el denominado "test de interés público", en la Decisión A115-09.

${ }^{27}$ En la aplicación de dicho método, el Consejo se refiere a LópEZ-AYLlón, Sergio - Posadas, Alejandro, Las pruebas de daño e interés público en materia de acceso a la información pública. Una perspectiva comparada, en Derecho Comparado de la Información, 9 (2007), pp. 23-24, en que señalan que en "circunstancias excepcionales en que el interés público justifique su divulgación" de la vida privada o patrimonio de las personas, autor citado en la decisión A115, c. $9^{\circ}$. En el sentido similar, GUіснот ReinA, Emilio, Derecho a la privacidad, transparencia y eficacia administrativa: un difícil y necesario equilibrio, en Revista Catalana de Dret Públic, 35 (2007), p. 61, sostiene que en las relaciones entre publicidad y reserva de la información en poder de la Administración "ha de ser resuelta como todo conflicto entre valores, bienes, derechos y libertades constitucionales, mediante una delimitación del alcance y contenido de cada uno de ellos y una ponderación que permita compatibilizarlos en caso de conflicto, alcanzando la solución que [...] entrañe el menor sacrificio posible de cada uno de ellos". 
[...] determinar si existe un interés público que justifique la divulgación de la información o si, por el contrario, debe prevalecer su reserva"28. Sin embargo, hay casos en que el test se ha aplicado explícitamente sin haber mediado la referida oposición o en que habiendo concurrido ésta tampoco ha operado una aplicación del test de interés público. En las pocas ocasiones en que la oposición de un tercero ha tenido lugar, la intimidad ha sido invocada por ellos sólo excepcionalmente ${ }^{29}$. Asimismo, veremos que hay decisiones en que el CT afirma que esta operando un "test de daño" cuando en verdad debería aplicarse un test de interés público.

Veremos, en primer lugar, algunos casos en que se aplicó formalmente el aludido test, invocándose como oposición el derecho a la intimidad, ya sea en su manifestación de información meramente privada, ya sea en su versión de información sensible. Luego, nos referiremos a las ocasiones en que el test se ha aplicado de modo explícito aunque sin haber mediado oposición de un tercero.

En el primer caso identificado (rol A29-09) el requirente pidió a la Dirección Nacional del Servicio Civil dar conocer los resultados de la evaluación personal suya y de quien había sido nombrado en el proceso de selección a un cargo público en el que el primero había participado. La información solicitada suponía tener acceso, entre otros antecedentes, a la evaluación sicológica y a las opiniones que terceros entregan sobre sus competencias. El ente requerido se negó a proveer la aludida información fundado en (a) la afectación del debido cumplimiento de las funciones que la ley encomienda al órgano requerido como, asimismo, en (b) la vulneración de la vida privada de los involucrados.

El Consejo, luego de aplicar el "test de daño"a la causal (a) y el test de

${ }^{28}$ CT, Decisión A244-09, c. $3^{\circ}$ : “[...] el Consejo ha estimado en casos anteriores (por ejemplo, en el amparo A115-09, de Patricio Herman con la I. Municipalidad de Providencia) que habiendo oposición de un tercero, como acontece en este caso, es indispensable verificar el daño que éste sufriría de entregarse la información y aplicar lo que en doctrina se ha llamado un 'test de interés público', a efectos de determinar si existe un interés público que justifique la divulgación de la información o si, por el contrario, debe prevalecer su reserva para resguardar los bienes jurídicos protegidos por la ley, concretamente los derechos del tercero que se opuso, en este caso, la autonomía sindical que, según la CUT sería vulnerada de publicarse la información requerida".

${ }^{29}$ En la Decisión A244-09, en que si bien la CUT -el tercero- se opuso a la entrega de las actas de recuento de votos de elecciones nacionales y provinciales de dicho organismo por estimar que eran "actos de carácter privado, nominados y con regulación propia”, el empleo de esta expresión se refiere más bien a un acto "privado" por ser objeto de una regulación especial, no en cuanto a tutelado por el derecho al secreto o reserva de las comunicaciones. 
interés público en la segunda $(\mathrm{b})^{30}$, concluyó que el provecho en "conocer la información solicitada es mayor que el daño que podría causar su revelación" ${ }^{\text {"31. }}$. En lo tocante a la eventual afectación de los derechos de la postulante seleccionada justifica la inclinación de la balanza a favor del derecho de acceso por cuanto estima de interés público "que se conozcan los antecedentes que acreditan el cumplimiento de los requisitos y perfiles necesarios para haber sido designado en dicho cargo" (estudios, experiencia laboral, logros laborales o académicos, entre otros,), ya que ello "acredita la idoneidad del mismo para desempeñarse en el cargo público" 32 .

Atendido lo señalado, el CT accede a la entrega de la información requerida con la única salvedad de "las referencias de los candidatos entregadas por terceros en el proceso de selección" pues tales "opiniones deben mantenerse en reserva aun cuando se haya adoptado la decisión, pues en caso contrario la sinceridad de estos testimonios se reduciría y les quitaría buena parte de su valor, de manera que en este caso el daño que originaría su difusión superaría las ventajas" 33 . Igualmente, el Consejo hace excepción de los "los datos sensibles de la persona seleccionada" ${ }^{34}$, debiendo esta información ser tarjada en virtud del principio de divisibilidad contemplado en el artículo 11, letra e) de la "Ley de transparencia". En similar sentido se pronunció la decisión A11009, tanto en relación a la información que autorizó dar a conocer como en cuanto a aquella que excepcionó de la luz pública, en un caso de selección de personal efectuado por el Servicio de Impuestos Internos.

En una decisión similar, rol A90-09, el requirente pidió ante la Dirección Nacional del Servicio Civil conocer información sobre el proceso de selección implementado para proveer dos cargos y, específicamente, la evaluación de sus antecedentes y su puntaje, así como de idénticos antecedentes de las personas que habían sido incorporadas en las nóminas de candidatos elegibles para tales cargos que seleccionó el Consejo de Alta Dirección Pública. El organismo requerido se negó a proveer la referida información basada principalmente en (a) la afectación del debido cumplimiento de las funciones que la ley encomienda al órgano requerido y en (b) la vulneración de la vida privada

${ }^{30}$ Aunque la decisión en cuestión se refiere en verdad al "test de daño" -en el c. 10, letra g)-, debiendo decir "test de interés público" al ponderar los derechos de la postulante seleccionada con el derecho de acceso, entendemos que se trata de un simple error de transcripción, también aplicable a la decisión A110-09 (casi idéntica a ésta).

${ }^{31}$ Decisión A29-09, c. 8 letra f).

${ }^{32}$ Ibíd., c. $10^{\circ}$, letra g) y f), respectivamente, por ambas citas. Esta decisión ha sido replicada, en cuanto a los fundamentos de la información a la que accede, por la A3509 , a modo meramente ejemplar.

${ }^{33}$ Ibíd., c. 8 letra f).

${ }^{34}$ Ibíd., c. 10, letra h). 
del propio solicitante como también de los derechos de los postulantes y de quien había sido evaluador externo.

Respecto de (a), el CT afirmó que se afectaría dicha causal, por lo que sostuvo la confidencialidad de determinados datos del informe psico-laboral del requirente como de la persona designada en el cargo ${ }^{35}$. En cuanto a (b), esto es, la eventual afectación de los derechos a la vida privada del requirente como de los postulantes seleccionados, el Consejo estimó la reserva de los mismos antecedentes recién aludidos ${ }^{36}$, además de las referencias de terceros dentro del proceso de selección, pues en caso de ser revelados públicamente "la sinceridad de estos testimonios se reduciría y les quitaría buena parte de su valor, de manera que el daño que originaría su difusión superaría a las ventajas de divulgar la información, lo que afectaría el debido cumplimiento de las funciones" ${ }^{37}$ del órgano requerido.

Llama la atención que en esta parte el Consejo haya razonado como si hubiese aplicado un "test de daño"(comparando las ventajas y desventajas de la transparencia versus el debido cumplimiento de las funciones del ente requerido) en circunstancias que aquí lo que se estaba analizando era la afectación de los derechos del requirente y de los postulantes al concurso público, por lo que conforme a la misma jurisprudencia del CT lo que debería haber operado era un test de interés público, esto es, un balanceo entre el derecho de acceso a la información pública y el derecho a la vida privada de los ya referidos involucrados ${ }^{38}$.

Por otra parte, la decisión C626-10 dice relación con la solicitud efectuada al Director Regional de Aduanas de Puerto Montt para que diera acceso a una serie de antecedentes, entre ellos, las querellas que dicho Servicio habría presentado en contra de tres funcionarios de la Municipalidad de la ciudad por su eventual participación en la internación ilícita de buses adquiridos por la entidad edilicia. Los funcionarios manifestaron su oposición para la entrega de copias de las querellas interpuestas en su contra como asimismo del documento que acreditaba el pago de la multa impuesta por Aduanas.

\footnotetext{
${ }^{35}$ Decisión A90-09, c. 7. Se refiere a los siguientes antecedentes: "referidos a la evaluación sicológica, la evaluación descriptiva de atributos y la conclusión (sintesis de fortalezas, oportunidades, debilidades y amenazas) del informe sicolaboral de los participantes en los procesos de selección a que se refiere este caso". Esto, considerando lo previamente resuelto en los casos A29-09 y A35-09.

${ }^{36}$ Ibíd., c. 8 y 9.

${ }^{37}$ Ibíd., c. 8, letra b).

${ }^{38}$ De hecho, en el c. 9, letra e), se afirma que "que no debe olvidarse que aunque este Consejo ha declarado que la esfera de privacidad de los funcionarios públicos es mucho más delimitada que la del resto de las personas en virtud de la función que ejercen no queda anulada y debe, en este caso, ser amparada", con lo cual reconoce que lo en tal punto estaba en juego era el derecho a la intimidad.
} 
Efectuado el pago de las aludidas multas, los referidos funcionarios solicitaron a Aduanas la renuncia de la acción penal a lo cual este organismo accedió desistiéndose de las respectivas querellas.

El Consejo dio lugar al acceso de los antecedentes requeridos en consideración a dos especies de argumentos. El primero se funda en la noción de "la menor intimidad de los funcionarios públicos". Esta idea sostiene que "que la esfera de privacidad del personal que trabaja para la Administración del Estado es más reducida que la del resto de las personas en virtud, precisamente, de las funciones que éstos ejercen" ${ }^{39}$. Este aserto ha sido ya una constante en la jurisprudencia administrativa del $\mathrm{CT}^{40}$.

La otra consideración se sostiene como resultado de la ponderación efectuada como resultado del test de interés público. Afirma "que, luego de aplicar el "test de daño" $y$ atendido el interés público que representa la información solicitada, ya que permite ejercer un adecuado control social del ejercicio de las funciones públicas, se considera que el beneficio de conocer la información solicitada es mayor que el daño que podría causar su revelación [...]"¹. Uno y otro argumento llevan a que el Consejo rechace las oposiciones deducidas por los funcionarios de la Municipalidad de Puerto Montt y autorice su acceso al requirente.

En otro caso (rol C816-10) el Ministerio de Educación recibe la solicitud de acceder a un largo listado de antecedentes relativos a los beneficiarios de subvenciones educacionales. El organismo se niega dar acceso al listado de "alumnos, por cada establecimiento, que son beneficiarios de la Subvención Especial Preferencial, debidamente individualizados con nombres y apellidos, en los años 2008 a 2010". Funda su negativa en que el "listado de alumnos con una situación socioeconómica vulnerable en su hogar y que habilitan al sostenedor para impetrar los beneficios de esta subvención, es un dato asociado a hechos o circunstancias de la vida privada". Añade el Ministerio que conforme la "Ley de transparencia" constituye "dato sensible el origen social de las personas" ${ }^{\$ 2}$, por lo que según la Ley $\mathrm{N}^{\circ} 19.628$, sobre Protección

\footnotetext{
${ }^{39}$ CT, Decisión C626-10, c. 11.
}

${ }^{40} \mathrm{La}$ misma C626-10 cita otras decisiones que han sustentado la noción de la menor esfera de vida privada de los funcionarios públicos: "[...] A47-09, de 15 de julio de 2009, A58-09, de 4 de agosto de 2009 y A95-09 y A327-09, ambas de 6 de noviembre de 2009, criterio que también se ha aplicado respecto de otros instrumentos de medición de desempeño (decisión A323-09, de 20 de noviembre de 2009), los registros de asistencia (decisiones A181-09, de 15 de julio de 2009, y C434-09, de 27 noviembre de 2009) y el curriculum vitae de algunos funcionarios (decisión C95-10)". Por nuestra parte hemos identificado otras que afirman lo mismo, a saber: C816-10.

${ }^{41}$ CT, Decisión C626-10, c. 11.

${ }^{42} \mathrm{CT}$, Decisión C816-10, $\mathrm{N}^{\circ}$ 5, letra j). La disposición a que alude el Ministerio es el inciso 2 del artículo 7, letra i) de la "Ley de transparencia". 
a la vida privada, dicha información no puede ser objeto de tratamiento ni comunicación salvo cuando la ley lo autorice o haya consentido el titular de los datos, ninguna de las cuales aquí ha concurrido, por lo que el organismo se opone a que a entregar tales antecedentes.

El CT, por aplicación del artículo 5 de la "Ley de transparencia", concluye que la casi totalidad de los antecedentes solicitados son "de naturaleza pública [...] que reviste un evidente interés para el control social de recursospúblicos, por cuanto dice relación con el otorgamiento de fondos públicos y con la rendición de cuentas asociada a la inversión de los mismos"43, por lo que a su respecto debe entregarse lo solicitado. En cuanto a la información denegada por el Ministerio por estimarla sensible, el Consejo concuerda en que se trata de información personal que "reviste especial sensibilidad por referirse a personas menores de edad" ${ }^{\prime 4}$. Por ello, procede a aplicar un test de interés público a fin de sopesar la "transparencia del otorgamiento de las subvenciones" con "el respeto a la protección de la vida privada de los menores de edad"45.

Efectuado el referido test, el CT estimó que "de no revelarse esta información -la información sensible, se refiere-no seperjudicaría substancialmente laposibilidad de ejercer un adecuado control social con respecto al otorgamiento de los fondos de la subvención [...] considerando los distintos medios de fiscalización dispuestos por la Ley" ${ }^{\prime \prime 6}$ que establece y regula las subvenciones, por lo que concluye que en este caso, "el beneficio público de revelar la información es inferior al perjuicio que se provocaría a los bienes juridicos involucrados" "7. Por tanto, concluyó que se configura la causal de reserva prevista en el artículo $21 \mathrm{~N}^{\circ} 2$ de la "Ley de transparencia".

Como lo adelantábamos, hay ejemplos en que el Consejo de todos modos lleva a cabo un balance -sustantivamente idéntico al test de interés público- aunque no se trate, formalmente hablando, del referido test, por no haber concurrido la oposición de un tercero. En otras ocasiones, la falta de la referida oposición de un funcionario público ha determinado que cierta información solicitada -los RUT, por ejemplo- que, a juicio del CT

${ }^{43}$ Ibíd., c. 12.

${ }^{44}$ Ibíd., c. 20. Apoya su aserto en doctrina que cita como asimismo en el artículo 5 inciso segundo de la Carta Fundamental en cuanto es un imperativo estatal respetar y promover los derechos, entre los cuales se encuentra aquellos reconocidos por la Convención de los Derechos del Niño, vigente en nuestro país.

${ }^{45}$ Ibíd., c. 24. También decide aplicar un "test de daño" para ponderar si la divulgación "puede generar un daño presente, probable y especifico a los intereses o valores protegidos de mayor entidad que los beneficios obtenidos".

${ }^{46}$ Ibíd., c. 25.

${ }^{47}$ Ibíd., c. 26. 
"podría afectar sus derechos" haya impedido "que este Consejo pueda realizar un test de interés público" ${ }^{\prime 8}$.

\section{Protección a LA INTIMIDAd SIN NECESIDAD DE INTERMEDIACIÓN DEL TEST INTERÉS PÚBLICO}

En el presente acápite, revisaremos que en ocasiones el CT ha procedido a brindar protección al derecho a la vida privada sin necesidad de recurrir al empleo del test de interés público.

En el primer ejemplo (rol A 53-09) frente a una solicitud de información acerca de expedientes relativos a multas aplicadas por la Dirección del Trabajo, el CT reconoce que a pesar de la publicidad de aquéllas, cierta parte de la información contenida en los expedientes solicitados podría contener datos personales -e incluso sensibles- de terceros que deberían ser protegidos $^{49}$. Añade que no se puede desconocer la naturaleza especial de las denuncias realizadas por los trabajadores ante la Dirección del Trabajo " $y$ el riesgo de que su divulgación, asi como la de la identidad de los denunciantes o la de los trabajadores que han declarado en un proceso de fiscalización en contra del empleador, afecte su estabilidad en el empleo o los haga victimas de represalias (especialmente si se mantienen laboralmente vinculados con el mismo empleador)" 50 .

Teniendo en consideración lo señalado, el CT concluyó que la publicidad o conocimiento de dicha información podía afectar derechos de terceros - de los trabajadores denunciantes o de los que han prestado declaración-, "en particular tratándose de la esfera de su vida privada y sus derechos de carácter económico emanados de la relación laboral" 51 , configurándose así la causal de reserva del artículo $21 \mathrm{~N}^{\circ} 2$ de la "Ley de transparencia", reforzada por la función que ésta (artículo 33, letra m) encomienda al Consejo, en orden a velar por el adecuado cumplimiento de la Ley $\mathrm{N}^{\circ} 19.628$, de protección de datos de carácter personal

Por su parte, la decisión C335-10 tiene relación con una solicitud, hecha a la Municipalidad de Renca, en que se pide acceso a la copia de una carta que

${ }^{48}$ CT, Decisión A10-09, c. $13^{\circ}$ (por ambas citas). El texto pertinente de este considerando dice: "[...] en opinión de este Consejo para adoptar esa decisión y revelar los R.U.T. habria sido necesario notificar a sus titulares conforme el articulo 20 de la "Ley de transparencia", pues se trata de información que actualmente no ba sido divulgada y que, de difundirse, podria afectar sus derechos, lo que no se hizo, impidiendo asi que este Consejo pueda realizar un test de interés público".

${ }^{49}$ Decisión A53-09, c. 11.

${ }^{50}$ Ibíd., c. 12.

${ }^{51}$ Ibíd., c. 13. 
denunciaba conductas que mancillaban la calidad profesional y honra del requirente. La misiva fue escrita por una abogada que, al momento de ocurrir los hechos, hacía su práctica profesional y era dependiente del solicitante. En su oposición la denunciante manifiesta que la eventual entrega de la carta al requirente lesionaría gravemente su derecho a la intimidad. El CT resuelve no dar acceso a una solicitud considerando que "el contenido del documento materia de la solicitud [...] seplasman opiniones y consideraciones de naturaleza asimilables a los de una denuncia", por lo que "resulta razonable el temor a que su divulgación afecte, por una parte, el ámbito de su vida privada y su salud, $y$, por otra desincentive el ejercicio de análogas denuncias a otras personas en similares circunstancias" 52 .

De este modo, replicando los criterios empleados en el caso A53-09, precedentemente expuesto, el Consejo rechaza la solicitud de acceso atendido que "la publicidad [...] de la información contenida en la carta solicitada puede afectar derechos de terceros [...], en particular tratándose de la esfera de su vida privada, lo mismo que su derecho a la salud"s3. Una particularidad de esta decisión es que no obstante haber concurrido la oposición de un tercero, el CT no llevó a cabo un test de interés público por estimar que no estaba suficientemente acreditado el hecho de que la carta escrita por la postulante -objeto de la solicitud de acceso- haya constituido el fundamento de la decisión de poner término al contrato en calidad de honorarios que mantenía el solicitante con la Municipalidad de Recoleta ${ }^{54}$.

Otro tanto se ha resuelto en el rol C198-10 frente a una solicitud en que se pedía al Ministerio de Salud informar, entre otros antecedentes, acerca de la individualización de un número determinado de pacientes aquejados por una enfermedad cuyas descompensaciones habrían sido atribuibles a alimentos elaborados por los laboratorios señalados en el requerimiento. Interpuesto el Amparo frente a la negativa de la referida entidad, el Consejo denegó, en lo que a esta parte se refiere, la información solicitada, como quiera que "se enmarca dentro de lo que la Ley de protección de datos personales define como 'datos sensibles', toda vez que se refiere a un determinado estado de salud físico de laspersonas sobre las que se consulta, en un periodo determinado de tiempo"s5 invocando la causal de reserva a la que se remite el artículo 21 $\mathrm{N}^{\circ} 5$ de la "Ley de transparencia", esto es, "[...] informaciones que una ley de quórum calificado haya declarado reservados o secretos, de acuerdo a las causales señaladas en el artículo $8^{\circ}$ de la Constitución Política" ${ }^{\prime 6}$.

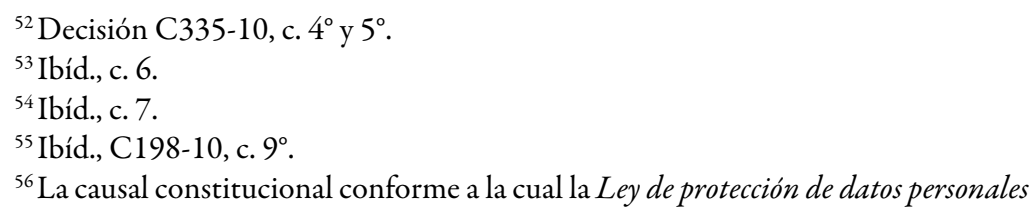




\section{VALORACIÓN CRÍTICA ACERCA DE LA PROCEDENCIA} DEL TEST DE INTERÉS PÚBLICO POR PARTE DEL CT

\section{1. ¿Posee el test de interés público sustento en la "Ley de transparencia"?}

Dilucidado que el test consiste en una especie de balanceo entre el interés en tutelar el derecho de acceso a la información pública y el interés en proteger el derecho afectado (vida privada, en este caso) ${ }^{57}$, y que dicha operación, según a lo manifestado por el CT, "debe respetar el principio de proporcionalidad" 58 , cabe preguntarse sobre la pertinencia de emplear un test en un ámbito cuya principal fuente legitimadora -la "Ley de transparencia" - no sólo no exige su empleo sino que lo rechaza de modo manifiesto aunque no explícitamente en su texto. Lo primero -que la "Ley" no lo exige- es un dato objetivo, como se verá. Lo segundo -que la "Ley" rechaza el uso de dicho test- es una opinión que fundamentaré en breve, pero que arranca en alguna medida de la anterior, por lo que ambas afirmaciones serán abordadas en conjunto.

a) El texto, contexto y la historia fidedigna de la "Ley de transparencia" no conciben el test de interés público. Esun hecho indiscutido que la "Ley de transparencia" no contempla mención alguna que pudiera dar pie para sostener la legitimidad acerca de la procedencia de aplicar un test o estándar que autorice limitar el ejercicio de derechos fundamentales(intimidad, honra, propiedad intelectual o industrial, entre otros) en beneficio de un objetivo constitucionalmente relevante (la transparencia pública) o en pos de otro derecho fundamental (el derecho de acceso a la información). Más todavía, la "Ley", en su texto e historia fidedigna, es clara en rechazar cualquier intento de justificar la vulneración de un derecho en pos de otro derecho o de un bien constitucionalmente relevante por la vía de aplicar un estándar que pretenda ponderar el costo- beneficio de infringir

declara información sensible "los estados de salud físicos o psíquicos" (artículo 2, letra g) es la protección de "los derechos de las personas" (artículo 8, inciso 2 C.Pol.) que en este caso es el derecho a la vida privada como motivo prevalente en este caso. Así lo confirma la misma decisión C198-10, al afirmar que la referida Ley de protección de datos "dice relación con la protección del derecho fundamental consagrado en el articulo $19 \mathrm{~N}^{\circ} 4$ de la Constitución Politica de la República, esto es, el derecho a la protección a la vida privada y a la honra de la persona y su familia" (considerando 7). Por lo demás, la información referente a la salud física y psíquica siempre se ha entendido en la doctrina y jurisprudencia predominante como parte integrante de la intimidad personal y familiar.

${ }^{57}$ La Decisión C193-10, c. $6^{\circ}$ ha manifestado que dicho test persigue "ponderar si el interés público a obtener con la entrega de información justifica su divulgación y vence [...] la reserva".

${ }^{58}$ CT, Decisión A45-09, c. $10^{\circ}$, replicada en A 115-09, c. $9^{\circ}$ y C402-09, c. 13, entre otras. 
uno de ellos (v. gr. la vida privada) versus idéntica comparación asociada a sacrificar el derecho de acceso a la información o la transparencia.

Así se desprende con meridiana claridad del inciso segundo del artículo 10 de la referida "Ley", disposición que establece que "[e]l acceso a la información comprende el derecho de acceder a las informaciones contenidas en actos, resoluciones, actas, expedientes, contratos y acuerdos, asi como a toda información elaborada con presupuesto público, cualquiera sea el formato o soporte en que se contenga, salvo las excepciones legales". Por su parte, el artículo 21, establece que las "unicas causales de secreto o reserva en cuya virtud sepodrá denegar total o parcialmente el acceso a la información" corresponde a una serie de derechos fundamentales o bienes públicos, entre los cuales la "Ley", en su número 2, prevé "los derechos de las personas", refiriéndose a modo ilustrativo a "su seguridad, su salud, la esfera de su vida privada o derechos de carácter comercial o económico".

Como es posible advertir, las disposiciones citadas de la "Ley" son inequívocas en establecer que el derecho de acceso a la información prevé su límite infranqueable en "los derechos de las personas" (también en ciertos bienes públicos de relevancia constitucional, v. gr., la seguridad nacional) sin contemplar hipótesis alguna que pudiera dar a entender que el sacrificio de cualquiera de ellos podría, ser bajo determinadas circunstancias, justificado con miras a fines ulteriores.

En el texto y contexto de la "Ley", dichas finalidades, análogas (otros derechos) o superiores (bienes constitucionalmente legítimos) configuran una excepción absoluta (no relativa) a la transparencia y al derecho de acceso a la información. Esto es particularmente lógico tratándose del derecho a la vida privada. No solo debido a que este derecho suele presentarse como la natural contrapartida del derecho de acceso a la información ${ }^{59}$ sino también porque el legislador previó no sólo que el CT promueva la transparencia y el ejercicio del derecho de acceso sino también el respeto a la vida privada. De hecho, varias legislaciones comparadas son explícitas en autorizar o denegar expresamente el test de interés público u otro similar cuando el derecho de acceso a la información aparece en tensión con la intimidad, como veremos enseguida.

Por otra parte, la historia fidedigna del establecimiento de la "Ley de transparencia" exhibe con claridad que si bien la moción parlamentaria que dio origen al texto hoy vigente previó de modo expreso la aplicación de un balanceo entre las causales de secreto o reserva (derechos fundamentales y

${ }^{59}$ Debido a esto es que varias legislaciones comparadas son explícitas en autorizar o denegar expresamente el test de interés público u otro similar cuando el derecho de acceso a la información aparece en tensión con la intimidad, como veremos enseguida. 
bienes constitucionales en juego) y el derecho de acceso a la información, el párrafo que contemplaba dicha posibilidad fue eliminado íntegramente en su trámite legislativo ante el Senado por lo que, en el aspecto en cuestión, dicha iniciativa no pasó a formar parte del texto que en definitiva fue aprobado, promulgado y publicado como Ley $\mathrm{N}^{\circ} 20.285$.

El referido texto, que brindaba sustento explícito para legitimar la procedencia de aplicar un test de interés público, decía lo siguiente, luego de referirse a las causales de reserva o secreto que podrían invocarse: "La calificación de reserva, total o parcial, establecida en las letras b) a e) deberá ser fundada y motivada, y sólo procederá sólo si el peligro de daño sobrepasa el interés público que promueve la transparencia y publicidad de los actos y documentos de la administración o en poder de ésta" ${ }^{\prime 60}$. Bajo esta redacción, la protección de la intimidad quedaba indudablemente condicionada al resultado de una labor ponderativa que estimase que el perjuicio a tal derecho fundamental sobrepasaba el interés público (la transparencia) promovido por el derecho de acceso a la información.

Así, en la perspectiva de esta fuente del Derecho - la "Ley de transparencia”- es evidente que, eliminado el ya aludido párrafo de su texto vigente ${ }^{61}$, lo dispuesto en éste se encuentra plenamente refrendado por la historia fidedigna de su establecimiento en cuanto a rechazar la aplicación de un estándar, como el test de interés público, en el evento que el derecho de acceso a la transparencia comprometa alguna de las causales de secreto o reserva establecidas en la Constitución y desarrolladas en la "Ley".

A mayor abundamiento, creemos que si el legislador de la "Ley de transparencia" hubiese querido admitir posibilidad de un test como el señalado lo debería haber establecido de manera explícita. Ello no solo por tratarse de una materia delicada en que están involucrados derechos fundamentales y bienes de relevancia constitucional, sino también porque por este mismo motivo asíse ha previsto - particularmente para el derecho a la intimidad- por la Ley de acceso a la información de Estados Unidos (en adelante, "FOIA estadounidense"), la normativa más antigua sobre la materia que data de 1966, y la Ley de acceso a la información del Reino Unido (en adelante, "FOIA inglesa"), vigente desde el año 2000, y que es una de las normas legales de derecho comparado que el legislador tuvo a la vista al estudiar la actual Ley.

En la misma línea, cabe añadir que el actual anteproyecto de Ley de acceso a la información, en España, admite expresamente "limitaciones proporcio-

${ }^{60}$ Moción Parlamentaria de los Senadores Jaime Gazmuri Mujica y Hernán Larraín Fernández. Fecha 4 de enero, 2005. Cuenta en Sesión 23, Legislatura 352, p. 9. Disponible en: http://www.bcn.cl/histley/lfs/hdl-20285/HL20285.pdf.

${ }^{61}$ Con ocasión de una indicación sustitutiva del Ejecutivo (que no dice relación con el test) el texto cambia sustancialmente en la Comisión Mixta, p. 409. 
nadas" al derecho de acceso, con la única salvedad de que se esté ante "datos sensibles" en cuyo caso la ley prohíbe un balanceo con el interés público. Nos referiremos luego sólo tangencialmente a esta información, ya que no se trata de un texto vigente y que, por lo demás, no pudo haberse tenido a la vista cuando se tramitó la "Ley de transparencia".

Las dos primeras normas legales de derecho comparado tratan cuidadosamente la relación entre el derecho de acceso a la información y los aspectos protegidos por el derecho a la vida privada. Sobre esto nos referiremos inmediatamente.

b) El test de interés público en la FOIA (Ley de acceso a la información) estadounidense e inglesa. El Anteproyecto de ley de acceso en España. De las nueve excepciones previstas por la FOIA estadounidense, sólo las referidas a la vida privada -la número 6 y 7 - admiten, a contrario sensu, injerencias justificadas en el ámbito de dicho derecho fundamental. En efecto, la salvedad número 6 excepciona expresamente del derecho de acceso a los "documentos personales, médicos u otros similares cuya revelación pública constituiria una clara e injustificada invasión a la privacidad"62. La excepción número 7 (C), incorporada en 1974, protege los documentos referidos a investigaciones efectuadas con propósitos disciplinarios ("law enforcement purposes") cuya revelación pública pudiera "constituir una "invasión injustificada de la privacidad personal"63.

Tanto los Informes del Senado norteamericano como de la respectiva Cámara de Representantes sobre la FOIA establecieron que la excepción $\mathrm{N}^{\circ}$ 6 exigía un "balanceo" entre el derecho a la intimidad y el interés público en obtener la información en poder del gobierno ${ }^{64}$. A modo ilustrativo, basta con señalar la parte pertinente del Informe emitido por el Senado de Estados Unidos en la tramitación de la FOIA y que refrenda el aludido requerimiento legal: "La frase 'clara e injustificada invasión a la privacidad personal' enuncia la aplicación de una medida que supondrá un balance de intereses entre la protección de los asuntos privados de una persona y la consecución del derecho del público a la información gubernamental"65.

${ }^{62}$ The Freedom of Information Act, 5 U.S.C. $\$ 552$, (b) 6, que establece que "esta sección no aplica" a una serie de materias que individualiza en 9 excepciones.

${ }^{63}$ Ibid., 5 U.S.C. $\$ 552$, (b) 7 (C). La referida excepción legal dice textualmente: “(7) records or information compiled for law enforcement purposes, but only to the extent that the production of such law enforcement records or information [...] $(C)$ could reasonably be expected to constitute an unwarranted invasion of personal privacy".

${ }^{64}$ Halstuk, Martin, Blurred Vision: The Supreme Court's FOIA Opinions on Invasion of Privacy, ahora en Davis, Charles N. - Splichal, Sigman L. (editores), Acces Denied. Freedom of Information in the Information Age (Iowa, Iowa State University Press, 2000), p. 125.

${ }^{65}$ S. Rep. $\mathrm{N}^{\circ} 813,89$ th Cong., $1^{\text {st. }}$. sess.9, 44. 
En la misma línea, la jurisprudencia de la Corte Suprema Federal -recogiendo la historia fidedigna de la FOIA ${ }^{66}$ - ha afirmado que la herramienta adoptada para resolver la tensión fue contemplar una excepción limitada a que la invasión en la intimidad personal no fuera "claramente injustificada" ${ }^{\prime 67}$.

Para aplicar las referidas excepciones, los órganos que ejercen jurisdicción tienen que determinar si los antecedentes requeridos encuadran dentro de la definición de "información personal o privada". Luego, deben ponderar el perjuicio que supone la injerencia en la vida privada con el beneficio que resulta de la revelación pública de la información requerida. Por último, para denegar la entrega de lo solicitado, la autoridad debe mostrar que la revelación pública "constituiria una clara e injustificada invasión a la privacidad" en el caso de invocarse la excepción $\mathrm{N}^{\circ} 6$, y una "invasión injustificada de la privacidad personal" si se tratase de la salvedad $\mathrm{N}^{\circ} 7$.

La FOIA inglesa, por su parte, contempla dos especies de excepciones al derecho de acceso a la información: las de carácter absoluto, que no admiten salvedad alguna ${ }^{68}$ bastando con que la información solicitada quede comprendida en la categoría singularizada por la excepción para que la autoridad pueda excusarse de entregarla ${ }^{69}$. Las excepciones relativas, en cambio, exigen por parte de la autoridad requerida la realización de un test de interés público. Cabe consignar que "[1] a Información de carácter personal protegida por la Ley de protección de datos de $1998^{\prime 70}$ constituye una excepción absoluta, no sujeta al referido balanceo.

Consecuencialmente, la regla es que si lo que se encuentra en juego es la afectación de la información protegida por la Ley de protección de datos

${ }^{66}$ El reporte del Senado en la tramitación de la referida Ley: "La frase 'clara e injustificada invasión a la privacidad personal' enuncia la aplicación de una medida que supondrá un balance de intereses entre la protección de los asuntos privados de una persona y la consecución del derecho del público a la información gubernamental", en Senador Rep. $N^{\circ} 813,93$ d Congreso. 2 d sesión. 11. (1974).

67 "Air Force v. Rose" 425 U.S. 352, 372 (1976). En los pocos casos en que, con posterioridad, la Corte Federal se ha pronunciado sobre la FOIA, este criterio no ha sido modificado.

${ }^{68} \mathrm{La}$ FOIA inglesa contempla, a modo ejemplar, las siguientes excepciones absolutas: Información accesible para el solicitante por otros medios (Section 21 a); Información provista o relacionada con organismos de seguridad (Section 23a); Documentos incorporados en procedimientos judiciales (Section 32).

${ }^{69}$ Brooke, Heather, Your Right to Know. How to Use the Freedom of Information Act and Other Access Laws (London, Pluto Press, 2005), p. 25. Afirma que la autoridad no está obligada, sin embargo, a rechazar la solicitud de acceso a la información. Se trata de una facultad y no de un deber.

${ }^{70}$ The Freedom of Information Act 2000, Section $40^{\mathrm{a}}$. 
-la información personal ${ }^{71}$ - ésta no puede, en caso alguno, ser entregada en respuesta a una solicitud de acceso basada en la FOIA (Section 40). Por lo mismo, ello tampoco debería ser posible en virtud de un test de interés público, toda vez que la aplicación de este estándar contribuiría a relativizar el carácter absoluto de esta excepción. De hecho, el sentido absoluto de ésta es tan categórica que cuando se ha afirmado que el contenido de los correos electrónicos de autoridades públicas podría ser comunicado, se arranca del supuesto básico de que el contenido difundible no es información privada sino aquella relacionada "con asuntos oficiales de la autoridad pública", esto es, información pública ${ }^{72}$.

Convengamos en que las dos versiones revisadas de legislación comparada, éstas han sido particular y especialmente cuidadosas al momento regular la relación entre el derecho de acceso a la información y el derecho a la intimidad. Bajo la formulación de la FOIA estadounidense se ha querido manifestar inequívocamente que el derecho de acceso se encuentra absolutamente limitado por los diversos aspectos de la vida privada que en la aludida ley se señalan, siempre que su publicación o comunicación equivalga a una clara e injustificada invasión a este derecho fundamental. De lo contrario, debe efectuarse un test de interés público entre ambos derechos. Para el caso de la FOIA inglesa, en cambio, es claro, que bajo ningún respecto el derecho a la intimidad, en su manifestación de datos personales, puede quedar expuesto, bajo un ejercicio de balanceo, a ser sacrificado a favor de la transparencia.

Respecto del Anteproyecto de Ley de acceso a la información en España, sólo cabe agregar que éste reconoce limitaciones al derecho de acceso, "cuando de la divulgación de la información personal pudiera resultar un perjuicio para: [...] i) La garantía de los derechos constitucionales [...] j) La vida privada y los intereses particulares legitimos" (artículo 5.1). Añade luego que las "limitaciones serán proporcionadas atendido su objeto y su finalidad de protección y se aplicarán a menos que un interés público superior justifique la divulgación de

${ }^{71}$ Data Protection Act 1998, Section I, que define "información personal" como aquella en virtud de la cual un individuo vivo puede ser identificado, ya sea por sí mismo o en conjunto con otra información que el controlador de la información ya posee o es probable que llegue a poseer.

${ }^{72}$ Information Commisioner's Office. Official Information Held in Private Email Accounts, p. 2, en que se dice que lo relevante es el contenido del e-mail, por lo que si contiene información que "se relaciona con asuntos oficiales de la autoridad pública", su ubicación en cuentas privadas no lo exime per se de las normas de la FOIA. En p. 3, el informe reitera que la "Información en cuentas de correo privadas que no dice relación con los asuntos de la autoridad pública no estará sujeta a la FOIA”. Disponible en: http:// www.ico.gov.uk/for_organisations/guidance_index/ /media/documents/library/ Freedom_of_Information/Detailed_specialist_guides/official_information_held_ in_private_email_accounts.ashx 
la información" (artículo 5.2). Con todo, prescribe que los datos personales íntimos constituyen un límite absoluto al derecho de acceso ${ }^{73}$, al regular que las "solicitudes de acceso [...] que contengan datos intimos o que afecten a la vida privada se denegarán, salvo que exista consentimiento expreso y por escrito del afectado, o una ley lo autorice", cerrando la puerta a una ponderación balanceadora entre los aspectos más íntimos de la vida privada y el derecho de acceso a la información.

En fin, y sin perjuicio de las diferencias existentes entre la FOIA estadounidense e inglesa, en ambas el derecho a la vida privada goza de una frontera que no es posible traspasar: por una parte, para la primera ley y la jurisprudencia sobre este punto, no es admisible una "invasión injustificada a la privacidad personal", mientras que para la FOIA inglesa, ningún grado de injerencia en "la Información de carácter personal" resultará legítimo. Esto cobra especial relevancia cuando autores citados por el Consejo ${ }^{74}$ han dicho que las leyes mexicana e inglesa "sirvieron de modelo para el diseño de la institucionalidad de acceso a la información chilena"7s.

Parece evidente que el efecto lógico de haberse eliminado completamente por el legislador el párrafo que autorizaba balancear el daño del derecho intervenido con el interés público que promueve la transparencia, es precisamente atribuirle a las causales de reserva o secreto un alcance de excepciones incondicionadas o absolutas. Esto es con mayor razón predicable cuando la causal de reserva es la intimidad, habida consideración de que en algunas importantes legislaciones comparadas la ponderación entre la vida privada y el derecho de acceso (o la transparencia) se prohíbe derechamente (FOIA inglesa) o queda condicionada expresamente a una clara y justificada invasión autorizada por ley (FOIA estadounidense).

No se discute que el Consejo pueda complementar su labor de adjudicación con distintos criterios jurídicos, pero cuando éstos emanan de una creación y práctica que, lejos de encontrarse legitimada por la jurisprudencia

${ }^{73}$ Como dice la Exposición de Motivos (el Mensaje) el Anteproyecto "cierra el acceso a la información pública que contiene datos relativos a la intimidad o la vida privada de las personas, salvo que el afectado lo consienta expresamente y por escrito, o lo autorice la Ley". El texto del Anteproyecto se encuentra disponible en:http://www. access-info.org/documents/Access_Docs/Advancing/Spain/Espana_Anteproyecto_ Ley_Transparencia.pdf

${ }^{74}$ Decisión A45-09, c. 8. Con todo, hemos identificado este caso como el único en que se cita el referido artículo.

${ }^{75}$ Tello, C. - Cerna, M. - Pavón, A., Acceso a la información pública: los desafíos del Consejo de la Transparencia, en Anuario de Derechos Humanos, 2009 (2010), p. 199. Sin embargo, este artículo que promueve el aludido test no hace referencia alguna al carácter absoluto de ciertas causales de reserva o secreto en la FOIA inglesa, que hacen improcedente el test en algunas materias. 
y la doctrina nacionales ${ }^{76}$, contraría su principal fuente del Derecho -la "Ley de transparencia" - desvinculándose de ella ${ }^{77}$, motivo que justifica de sobra una revisión acerca de los fundamentos que sustentan la procedencia del referido test de interés público.Esta carencia se hace más problemática desde que la formulación y aplicación del test de proporcionalidad no es pacífica en el derecho comparado ${ }^{78}$, ni siquiera entre aquellos que proclaman su utilización ${ }^{79}$. Además, como veremos, el CT tampoco sigue estrictamente los requisitos operativos del estándar al que adhiere.

\section{2. ¿Ha sido el CT coherente consigo mismo al emplear el test de interés} público?

La perspectiva que abordaremos dice relación con la valoración del servicio que ha prestado para el Consejo la aplicación de este test conforme a sus propias decisiones. Nuestra respuesta será negativa, como quiera que estimamos que el CT no ha sido coherente consigo mismo al aplicar el aludido estándar, del modo en que este organismo lo ha formulado en parte de su jurisprudencia administrativa.

Hemos revisado precedentemente que el CT ha proclamado invariablemente el test de interés público como un instrumento determinante para evaluar si los antecedentes solicitados en virtud del derecho de acceso a la información han de ser públicamente revelados en los casos en que

${ }^{76}$ Hay en día un test similar al de interés público (el principio de proporcionalidad) sólo tiene una aplicación habitual en materia laboral. Las ocasiones en que el Tribunal Constitucional efectivamente ha empleado la proporcionalidad no exceden de la decena. Un recuento de estos en la jurisprudencia del TC en Covarrubias Cuevas, Ignacio, El bien común, el interés público o los fines constitucionalmente legitimos como justificaciones del regulador para limitar los derechos fundamentales, ahora en ARANCIBia - Martínez - Romero (coordinadores), Litigación pública (Santiago, AbeledoPerrot - Thomson Reuters, 2011), pp. 411-420. Sin embargo, este panorama podría cambiar si algunas disidencias se transformaran en mayoría.

${ }^{77}$ Aldunate Lizana, Eduardo, Aproximación conceptual y critica al neoconstitucionalismo, en Revista de Derecho de la Universidad Austral de Chile, 23 (2010) 1, p. 96. Hacemos nuestra las críticas que hace al principio de proporcionalidad. Entre otras, señala que las razones en virtud de las cuales opera el juicio de ponderación son independientes de los principios presentes en el texto constitucional "y, por tanto, se encuentran del todo desvinculadas de la fuente jurídica de la decisión”.

${ }^{78}$ Stone, Alec - Mathews, Jud, Proportionality Balancing and Global Constitutionalism, en Columbia Journal of Transnational Law, 47 (2009), pp. 73-163. Este trabajo también da cuenta de los matices sobre el test de proporcionalidad en distintos Tribunales Constitucionales.

${ }^{79}$ Sobre las diferencias entre dos modos de concebir el principio de proporcionalidad por la doctrina europea e inglesa, RIvers, Julian, Proportionality and variable intensity of review, en Cambridge LawJournal 65, (2006), pp. 174-207. 
dicha comunicación pueda vulnerar los derechos de las personas ${ }^{80}$. Llama la atención, sin embargo, que el Consejo haya dejado de emplearlo en algunos casos en que ha concurrido la hipótesis sustantiva que el mismo organismo ha adoptado para sustentar su aplicación y, desafortunadamente lo ha hecho sin justificar esta omisión.

En efecto, para que tenga lugar la aplicación de este criterio de interés público, el supuesto básico, de orden sustantivo ${ }^{81}$, es que como consecuencia del ejercicio del derecho de acceso a la información pueda efectivamente derivarse un daño al contenido de un derecho fundamental, perjuicio que puede ser real o potencial, aunque en todo caso debe ser serio. La circunstancia que el derecho de acceso termine finalmente imponiéndose o no al derecho vulnerado dependerá de la ponderación balanceadora que lleve a cabo el Consejo luego de operar el aludido test, lo cual corresponde ya a un fase operativa distinta de la referida hipótesis central.

Sin embargo, en algunos casos en que se ha detectado que es la intimidad el derecho fundamental que se ha visto amenazado con la revelación pública de la información requerida, el Consejo ha resuelto brindar protección a la vida privada sin siquiera haber invocado al test de interés público ${ }^{82}$. En otras ocasiones en que lo ha proclamado tampoco lo ha aplicado verdaderamente. Una particularidad no menor exhibida en aquellos casos en que se ha resguardado la intimidad sin test es que el CT ha estimado que aquello que ha sido vulnerado o se encuentra bajo serio riesgo de padecerlo son los "datos sensibles" de un tercero, haya o no éste ejercido su derecho de oposición.

Así, en ocasiones el Consejo, no sólo ha omitido aplicar el test que ha proclamado con un carácter general, sino que en aquellos casos en que lo ha invocado y aplicado expresamente, tampoco ha sido fiel a la formulación que

${ }^{80}$ Desde la decisión A115-09, c. 9, en que se afirmó: “[...] conviene considerar que cuando la transparencia puede exponer la vida privada o el patrimonio de las personas, la doctrina y la legislación comparada entienden que en principio existe una barrera que restringe la divulgación de los documentos que contienen esta información. Pese a ello [...] pueden existir circunstancias excepcionales en que el interés público justifique su divulgación. Estas circunstancias excepcionales suponen una dificil y compleja valoración de los intereses en juego. Algunos paises han previsto en sus legislaciones los estándares que guian esta ponderación y que se conocen como la prueba de interés público" [López - Ayllón, Sergio - Posadas, Alejandro, cit. (n. 27), pp. 23-24] (la cursiva corresponde al original). Este considerando ha sido reiterado en las decisiones C402-09, c. 13; C439-09, c. 9 y C533-10, c. 4 (citado parcialmente aquí), a modo meramente ilustrativo.

${ }^{81}$ No nos referiremos a aquellos casos en que el CT ha omitido el empleo del test por un motivo procedimental, esto es, por no haber concurrido la oposición de un tercero, a pesar que el Consejo tampoco ha sido del todo uniforme en la aplicación de este criterio adjetivo.

${ }^{82}$ Decisiones A53-09, C335-10 y C198-10, a modo ejemplar. 
él mismo ha adoptado sobre del estándar en cuestión. Recordemos que en varias decisiones dicho organismo ha afirmado que este criterio "debe respetar el principio de proporcionalidad", lo cual "supone analizar, conforme señala la doctrina: a) si la medida es eficaz, b) si no existe un medio más moderado para la consecución eficaz del propósito buscado (en este caso, cautelar el secreto) y, por último, c) si de la medida a adoptar (en este caso, el secreto absoluto) derivan más beneficios o ventajas para el interés general que perjuicios sobre otros bienes $o$ valores en conflicto" 83 .

De este modo, el test de proporcionalidad no ha sido respetado del modo que allí se indica ni tampoco de la manera como generalmente se ha entendido. No hemos detectado decisión alguna en la que el CT se haya ajustado al test tripartito o de cuatro sub-principios escalonados a que se refieren las decisiones citadas y que lleva consigo la aplicación del principio de proporcionalidad como método de resolución de conflictos entre derechos fundamentales o entre éstos y bienes de relevancia constitucional. Estas exigencias son pacíficamente compartidas por quienes suelen proclamar la universalidad $^{84}$ del test como, asimismo, de sus requisitos operativos ${ }^{85}$.

En vez de hacer operar el test de proporcionalidad en sentido amplio, lo

${ }^{83}$ Decisiones, A45-09, c. 10, A165-09, c. 17, letra b), ii, número 9, a modo ilustrativo (por ambas citas).

${ }^{84}$ Alexy, Robert, Epilogo a la teoría de los derechos fundamentales (traducción de Carlos Bernal Pulido), en REDC., 66 (2002), pp. 13-64. En el mismo sentido> BEATTY, David M, The Ultimate Rule of Law (New York, Oxford University Press, 2004), p. 162 y Kumm, Mattias, The Idea of Socratic Contestation and the Right to Justification: The Point of Rights Based Proportionality Review, Law \& Ethics Human Rights4, (2010), p. 144.

${ }^{85} \mathrm{Sin}$ perjuicio de las diferencias que perfilan sus distintas aproximaciones, la proporcionalidad suele presentarse bajo la fórmula de tres sub-principios cada uno de los cuales expresa una exigencia que toda injerencia de autoridad estatal en los derechos debe satisfacer. La idoneidad, persigue verificar que los medios adoptados por la autoridad sean aptos para alcanzar un fin constitucionalmente legítimo. Como ésta expresa dos requisitos diversos -la idoneidad del medio y la licitud del fin-algunos dividen éste en dos. La segunda exigencia, la necesidad, consiste en la aplicación del medio menos lesivo para el fin lícito. Cumplidos los pasos precedentes, el tercero, la proporcionalidad en estricto sentido, supone el ejercicio de balancear los beneficios de la medida impuesta versus los costos de haber incurrido en la vulneración de un derecho fundamental para concluir en qué lado se produce el mayor bien. Al respecto, véase: BARNES, Javier, Introducción al principio de proporcionalidad en el Derecho comparado y comunitario, en Revista de Administración Pública, 135 (1994), pp. 500-501; Bernal Pulido, Carlos, El principio de proporcionalidad y los derechos fundamentales (Madrid, Centro de Estudios Políticos y Constitucionales, 2003), pp. 36-37; Stone, Alec- Mathews, Jud, cit. (n. 78), pp. 53-66; Nogueira Alcalá, Humberto, El principio de proporcionalidad y su aplicación en Sudamérica por la jurisdicción constitucional, con especial mención al Tribunal Constitucional Chileno, en CARBONELL, Miguel (coordinador), 
que el Consejo ha hecho con cierta habitualidad es llevar adelante sólo "una aplicación específica del principio de proporcionalidad" 86 , esto es, el tercer subprincipio del criterio en cuestión, conocido como "la proporcionalidad en

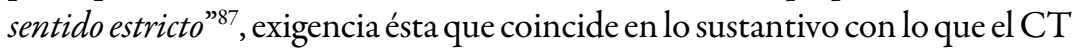
ha dicho que debe efectuarse: "realizar un balance entre el interés de retener la información y el interés de divulgarla para determinar si el beneficio resultante de conocer la información solicitada es mayor que el daño quepodría causar su revelación, concretamente los derechos del tercero que se opuso [...]"88.

En esta línea parecería inscribirse la última tendencia de la jurisprudencia administrativa del CT, al sostener que para dar lugar al derecho de acceso a la información invocado por el solicitante, "deberá existirproporcionalidad entre los daños que la publicidad provoca a alguno de los bienes jurídicos protegidos por las causales de secreto o reserva y el perjuicio que el secreto causa al libre acceso a la información y al principio de publicidad"s9. En tal sentido, se han pronunciado, de manera creciente, las decisiones del referido organismo ${ }^{90}$.

Esta modalidad de hacer operar parcialmente el principio de proporcionalidad es rechazada por quienes adhieren a este modo de adjudicación constitucional y, consecuencialmente, por los autores reiteradamente citados por el Consejo - Bernal Pulido (de Colombia) y García y Contreras (de Chile) - en varias decisiones en las cuales el organismo ha hecho exactamente lo contrario a lo sostenido por éstos, como por la doctrina en general, en lo que a la satisfacción de las exigencias del indicado test se refiere.

En efecto, los aludidos autores han sido claros en señalar que el test de proporcionalidad supone el cumplimiento escalonado y copulativo de los

El principio de proporcionalidad en la interpretación jurídica (Santiago, Librotecnia, 2010), pp. 353-403.

${ }^{86}$ Decisión A297-09, c. 14.

${ }^{87}$ Para Bernal Pulido, Carlos, cit. (n. 85), p. 36, conforme a la proporcionalidad en sentido estricto, "las ventajas que se obtienen mediante la intervención en el derecho fundamental deben compensar los sacrificios que ésta implica para sus titulares y para la sociedad en general". En sentido similar, Clerico, Laura, El examen de proporcionalidad: entre el exceso por acción y la insuficiencia por omisión o defecto, ahora, en CARBONELL, Miguel (coordinador), El principio de proporcionalidad en la interpretación jurídica (Santiago, Librotecnia, 2010), p. 190, afirma que esta regla dice: "Cuando (el medio establecido es idóneo y el menos lesivo) el peso de los argumentos que hablan a favor de la importancia del fin estatal legítimo [...] sobrepasa el peso de los argumentos que hablan a favor de evitar la intensidad de la restricción iusfundamental, entonces la medida estatal es proporcional". Si no se cumplen estos requisitos, "la medida estatal no es proporcional en sentido amplio".

${ }^{88}$ Decisión C533-10, c. 3.

${ }^{89}$ Decisión C874-11, c. 10.

${ }^{90}$ En sentido idéntico o similar, DecisionesA45-09, c. 8 y ss.; C734-10, c. 4; y C55811, c. 4, entre otros. 
sub-principios que lo configuran. De hecho, el mismo Bernal Pulido citado por el CT ha sido categórico en sostener que "[s]i una medida de intervención en los derechos no cumple las exigencias de estos tres sub principios, vulnera el derecho fundamental intervenido y por esta razón debe ser declarada inconstitucional" ${ }^{91}$. Con la misma claridad se ha pronunciado la doctrina ${ }^{92} \mathrm{y}$, en la misma dirección han apuntado García y Contreras, tanto en el artículo al que con frecuencia ha recurrido el Consejo ${ }^{93}$ como, asimismo, en otros trabajos suyos en que el test de proporcionalidad ha sido analizado con mayor detalle y precisión ${ }^{94}$.

Así, desde una perspectiva estrictamente procedimental, al no satisfacerse por el CT las exigencias, pacíficamente compartidas por sus adherentes, en cuanto al cumplimiento integral del test de proporcionalidad, ni tampoco con aquel requisito de orden sustantivo, proclamado por el mismo Consejo en varias de sus decisiones, la intervención autorizada en el ámbito del derecho a la intimidad debe estimarse desproporcionada y, por tanto, inconstitucional. En adelante, nos pronunciaremos sobre la desproporción que, en términos más bien sustantivos, puede recaer sobre el derecho a la vida privada con ocasión del empleo del test de interés público, reducido a la sola faz de la proporcionalidad en estricto sentido.

3. ¿Puede el sacrificio de los "datos sensibles" seguirse como una consecuencia lógica del ejercicio del derecho de acceso?

Ya hemos dicho que no puede prestar un buen servicio un test que el órgano que lo hace operar no lo aplica del modo en que afirma que debe aplicarse y cuya omisión conduce en la inconstitucionalidad de la medida de

${ }^{91}$ Bernal Pulido, Carlos, cit. (n. 85), p. 37.

${ }^{92}$ BARnes, Javier, El principio de proporcionalidad. Estudio preliminar, en Cuadernos de Derecho Público, 5 (1998), pp. 15-49; GRIMm, Dieter, Proportionality in Canadian and German Constitutional Law Jurisprudence, en University of Toronto Law Journal, 57 (2007), pp. 383-395; STONE, Alec - MATHEws, Jud, cit. (n. 78), p. 75, para quienes: "el análisis involucra cuatro pasos", reconociendo que algunas Cortes -generalmente en Europa Continental- prevén tres exigencias, al omitir "el propósito constitucionalmente legítimo"; Díaz García, Iván L., Aplicación del principio de proporcionalidad en orden a juzgar sobre la licitud o ilicitud de una restricción a derechos fundamentales, en Revista de Derecho de la Pontificia Universidad Católica de Valparaiso, $36\left(2011\right.$, semestre $\left.1^{\circ}\right)$, p. 174.

${ }^{93}$ García, Gonzalo - Contreras, Pablo, Derecho de acceso a la información en Chile: nueva regulación e implicancias para el sector de la Defensa Nacional, en Estudios Constitucionales, 7 (2009), p. 144.

${ }^{94}$ GARcía, Gonzalo, Teoría constitucional sobre los límites al ejercicio de los derechos fundamentales (Tesis doctoral, Universidad Carlos III, Getafe, Madrid, 2005) p. 361 (inédita). 
intervención estatal en el derecho fundamental comprometido. Ahora, en una línea de argumentación menos procedimental que la precedentemente expuesta, sostendremos que no puede brindar un buen servicio un parámetro -la proporcionalidad en sentido estricto- cuya formulación incentiva una balanceo sin cuartel que ciertamente introduce un escollo a la labor, legalmente prevista para el Consejo, de entregar no sólo una efectiva tutela al derecho de acceso a la información sino también de resguardar la vida privada, especialmente aquellos aspectos más sensibles de la intimidad, que suelen verse contrapuestos al primero y que, a nuestro juicio, no pueden quedar entregados a una operación intelectual ponderativa de costo-beneficio, exigida conforme la prescripciones del denominado sub-principio de proporcionalidad en sentido estricto.

Ya señalamos que la referida exigencia del test de proporcionalidad -denominada también la "regla de ponderación"- conlleva un análisis en que "las ventajas que se obtienen mediante la intervención en el derecho fundamental deben compensar los sacrificios que ésta implica para sus titulares y para la sociedad en general"'s5. Aplicado esto al derecho de acceso a la información supone, como ha dicho el CT, "ponderar si el interés público a obtener con la entrega de información justifica su divulgación y vence [...] la reserva" ${ }^{\circ}$ o "si el beneficio resultante de conocer la información solicitada es mayor que el daño que podría causar su revelación, concretamente los derechos del tercero que se opuso [...]"'97.

Como se advierte en esta fase operativa del test, es la relevancia de la realización del fin perseguido por la intervención en el derecho fundamental lo que debe justificar la importancia o gravedad de la referida intervención en el derecho ${ }^{98}$. En los casos expuestos, se trata que la importancia del fin a obtener -la transparencia pública vía el ejercicio del derecho de acceso a la información-mediante la intervención en la vida privada de un tercero (o incluso de un funcionario público) termine sobrepasando, mediante un

${ }^{95}$ Bernal Pulido, Carlos, cit. (n. 85), p. 36.

${ }^{96}$ Decisión C193-10, c. 6.

${ }^{97}$ Decisión C533-10, c. 3.

${ }^{98}$ Alexy, Robert, Teoría de los derechos fundamentales (traducción de Ernesto Garzón Valdés, Centro de Estudios Políticos y Constitucionales, Madrid, 1997), p. 161, lo explica con mayor detención: "Cuanto mayor es el grado de la no satisfacción o de afectación de uno de los principios, tanto mayor debe ser la importancia de la satisfacción del otro". Luego detalla los pasos de la proporcionalidad en sentido estricto en ALEXY, Robert, Epilogo, cit. (n. 84), p. 32: "En el primer paso es preciso definir el grado de la no satisfacción o de afectación de uno de los principios. Luego, en un segundo paso, se define la importancia de la satisfacción del principio que juega en sentido contrario. Finalmente, en un tercer paso, debe definirse si la importancia de la satisfacción del principio contrario justifica la afectación o la no satisfacción del otro". 
cálculo utilitarista, la gravedad de la injerencia padecida por el derecho a la intimidad.

¿Es sostenible que el sacrificio del derecho a la intimidad se siga como una consecuencia lógica del ejercicio del derecho de acceso habida consideración de la identificación de éste con el interés público en la transparencia de los actos gubernamentales? La respuesta es ciertamente negativa, desde una triple perspectiva.

En primer lugar, desde el prisma de la "Ley de transparencia", el que ésta haya sido diseñada para la consecución de un objetivo de indubitada relevancia constitucional, como es la publicidad de la actividad de los órganos del Estado (artículo 8, inciso $2^{\circ}$ C.Pol.), no se deriva que la obtención de dicha finalidad pueda hacerse a costa de los derechos fundamentales. Así lo manifiestan con claridad dos disposiciones troncales de la "Ley" que aseguran la "transparencia de la función pública" (artículo 5) y el "acceso a la información" (artículo 10) con la salvedad de las excepciones legales (dispuestas en ambas disposiciones) dentro de cuales están comprendidos los derechos de las personas y otros bienes constitucionales de relevancia como la seguridad nacional, entre otros.

Bajo esta comprensión, los instrumentos contemplados por la "Ley de transparencia" para promover la satisfacción de su finalidad propia, esto es, los principiosde relevancia, de libertad de información, de apertura, de máxima divulgación", entre otros, excluyen expresamente "aquello que esté sujeto a las excepciones constitucionales o legales" 100 , por lo que tampoco puede ser utilizados como argumentos en beneficio de un balanceo incontrarrestable en favor de la transparencia pública. De otro modo no se entendería que junto al objetivo de promover y hacer cumplir la "transparencia de la función pública" el CT también tiene por misión legal "velar por la debida reserva de los datos e informaciones que conforme a la Constitución y a la ley tengan carácter secreto o reservado" como también "por el adecuado cumplimiento de la ley $N^{\circ} 19.628$, de protección de datos de carácter personal", entre los cuales se resguarda el tratamiento y develación de los "datos sensibles"101.

${ }^{99}$ Ley No 20.285, artículo 11, letras a), b), c) y d) (por todas).

${ }^{100}$ Esta redacción corresponde sólo a la salvedad del principio de máxima divulgación, de la letra d) de la citada disposición legal. Los otras letras b y c) lo expresan refiriéndose análogamente a las "excepciones o limitaciones establecidas por leyes de quórum calificado" o a las "a las excepciones señaladas", respectivamente. La letra a) no hace salvedad en este aspecto.

${ }^{101}$ Ley No 19.628, sobre: Protección de la vida privada o protección de datos de carácter personal, Diario Oficial de 28 de agosto de 1999, cuyo artículo 2, letra g) define los datos sensibles como "aquellos datos personales que se refieren a las caracteristicas físicas o morales de las personas, tales como los hábitos personales, el origen racial, las ideologías 
Este aspecto del diseño legislativo de la "Ley" se cohonesta adecuadamente con los criterios sustantivos constitucionalmente exigibles, entre los cuales los artículos 1 inciso $4^{\circ}$ y $19 \mathrm{~N}^{\circ} 26$ C.Pol. permiten conciliar las indispensable limitaciones en los derechos (vida privada) en pos del bien común o manifestaciones de éste (transparencia pública) a condición que dicha injerencias no importen un sacrificio de la esfera medular -los datos sensibles- del derecho intervenido (conforme a lo dispuesto por la prohibición al legislador como a toda autoridad de afectar el contenido esencial de los derechos o de impedir su libre ejercicio). Sobre este punto nos referiremos mayor extensión más adelante.

La segunda parte de la respuesta, negativa, la adelanta el propio Consejo en aquellos casos en que ha tenido que rehusar derechamente a emplear el test de interés público para brindar una eficaz tutela a los datos sensibles, como se precisa con anterioridad. Como se vio, precisamente en los contados casos en que se llegó a la conclusión que la transparencia no sobrepasaba a determinados aspectos esenciales del derecho a la intimidad, el CT omitió la invocación y el empleo del test de proporcionalidad o de una parte de éste.

El Consejo también contribuye a responder negativamente la interrogante recién formulada en aquellas ocasiones en que habiendo recurrido formalmente al test, no lleva a cabo análisis sustantivo alguno en que se haya procurado abordar, como lo obliga el test -más allá de ciertos razonamientos del tipo "se considera que el beneficio de conocer la información solicitada es mayor que el daño que podría causar su revelación"- si la relevancia del fin (la transparencia) o del derecho (de acceso a la información) promovido justificaba el grado de compromiso padecido por la intimidad, aunque tal injerencia no haya llegado al punto de afectar el contenido esencial del derecho o impedir su ejercicio, según lo previsto en el artículo $19 \mathrm{~N}^{\circ} 26 \mathrm{C}$.Pol.

Desde esta perspectiva, el saldo es negativo como quiera que el propio CT ha demostrado que el test de interés público no sirve para todos los casos $y$, por tanto, carece de aquella pretensión de universalidad que, veremos, le atribuyen sus adherentes.

La tercera respuesta a la pregunta planteada tampoco es positiva, al estimarse, ya en un plano más bien deontológico, que la operativa efectuada por el Consejo, unido a la aplicación del subprincipio de proporcionalidad, allanan fácilmente el camino hacia una prevalencia casi incondicionada del derecho de acceso a la información en perjuicio del derecho a la vida privada. Y, como hemos visto en algunas ocasiones, se trata de una prevalencia que se traduce enun menoscabo desmedido (desproporcionado) como igualmente lo son

y opiniones politicas, las creencias o convicciones religiosas, los estados de salud físicos o psiquicos y la vida sexual". 
aquellos presupuestos bajo los cuales el CT lleva a cabo su labor ponderativa de derechos y bienes constitucionales. Todo esto, con la salvedad - relativa a los datos sensibles- a la que nos referiremos más adelante.

En efecto, al no considerar las dos primeras exigencias del test de proporcionalidad -los sub principios de adecuación y de necesidad-el Consejo tiende a dar por sentado que el derecho de acceso a la información, invocado por el solicitante, es idón eo para la satisfacción del objetivo de la transparencia pública. Paralelamente, al no llevar a cabo un examen acerca del cumplimiento del requisito de necesidad, dicho organismo omite la relevante cuestión relativa a si la limitación padecida por el derecho a la vida privada es, de todas las alternativas posibles, la menos restrictiva para la consecución de la señalada finalidad.

En varias ocasiones, aunque el Consejo no lo ha advertido de este modo, la aplicación del principio de divisibilidad reconocido en la "Ley"102 ha operado una función análoga a la que habría correspondido efectuar conforme al sub principio de necesidad del test. A modo ilustrativo, hay casos en que habiendo sido solicitado el acceso a la información contenida en un contrato administrativo, el CT ha autorizado la develación de dicho acto con excepción de determinados antecedentes personales, ya sea por su carácter sensible, ya sea porque de conformidad a los hechos del procedimiento en cuestión no presta servicio alguno conocer de ellos ${ }^{103}$. El punto es que este resultado se ha llegado no gracias a la proporcionalidad sino que a pesar de ella, como veremos en nuestras objeciones a la tercera fase del test.

Descontados los dos primeros requisitos, que no constituyen sino resguardos que miran al interés del derecho intervenido, el camino se encuentra bastante despejado para que bajo la tercera exigencia -la proporcionalidad en sentido estricto- la transparencia se imponga al derecho a la intimidad, tornándose prácticamente incontrarrestable el embate del primero sobre el segundo. En una dinámica en que no se cumple ninguno de los dos primeros pasos del test, ocurre que el Consejo tampoco aplica el tercer requisito conforme al presupuesto sustantivo proclamado por aquellos que comparten una noción "optimizadora" del criterio de proporcionalidad.

La referida noción, como lo adelantáramos, arranca del supuesto básico que el balanceo a efectuarse entre dos derechos o entre éstos y un bien constitucionalmente legítimo, conlleva un análisis de costo-beneficio entre las ventajas, que para el derecho de acceso, provienen del sacrificio al derecho a la intimidad. Este examen implica justificar en qué medida la ventaja (trans-

${ }^{102}$ Ley No 20.285, artículo 11, letra e) "conforme al cual si un acto administrativo contiene información que puede ser conocida e información que debe denegarse en virtud de causa legal, se dará acceso a la primera y no a la segunda".

${ }^{103}$ CT, Decisiones A29-09, c. 10, letra h; A110-09 y C711-10, a modo ejemplar. 
parencia) que supuestamente se obtiene mediante la injerencia en el derecho a la vida privada compensa los sacrificios que ésta implica para sus titulares y para la sociedad en general ${ }^{104}$, operación ésta que supone, al menos, definir si la importancia de la satisfacción del derecho o bien contrario justifica, por su gravedad, la afectación o la no satisfacción del otro bien o derecho ${ }^{105}$.

Dilucidado lo anterior, es pertinente formular la siguiente pregunta: ¿cabe llevar adelante un análisis balanceador de costo versus beneficio en circunstancias de que lo que se trata de ponderar son bienes o derechos que no son susceptibles de ser evaluados bajo un criterio exclusiva o primordialmente utilitarista?

La observación planteada, que también es extensible a otros órganos de jurisdicción especializada ${ }^{106}$, se sustenta en el presupuesto de que difícilmente puede operar la proporcionalidad -particularmente en sentido estrictocuando lo que debe someterse a balanceo son aspectos $i$ ) no mensurables y ii) inviolables de bienes humanos básicos y concretos como el derecho fundamental a la intimidad. Sobre lo primero, cabe preguntarse sobre la posibilidad racional de medir o comparar aspectos del bienestar humano que son inconmensurables.

¿Cómo puede arribarse a la conclusión de que los sacrificios padecidos por el titular del derecho a la vida privada son compensados por el beneficio que (supuestamente) irroga para la sociedad (agregativamente) como para el titular del derecho de acceso la circunstancia de haber acogido su solicitud?

Para ilustrar la interrogante con otros ejemplos de aspectos inconmensurables de los derechos: ¿puede resolverse en términos de costo-beneficio, si el indudable fin estatal de la prevención de la pornografía infantil justifica escudriñar la intimidad de los cibernautas por la vía de conocer los sitios que visitan en internet. ¿Puede el interés público en proteger la moralidad de los menores de edad dejar entregada la vida privada a un cálculo de proporcionalidad? O, más problemático todavía, ¿en qué sentido podría concluirse que el beneficio obtenido por una política pública de salud puede compensar el costo de dejar sin tutela a la criatura que se encuentra en el vientre materno? ${ }^{107}$

${ }^{104}$ Bernal Pulido, Carlos, cit. (n. 85), pp. 36-37.

${ }^{105}$ Alexy, Robert, Epílogo, cit. (n. 84), p. 32.

${ }^{106}$ Algunas observaciones críticas al test de proporcionalidad en el Tribunal Constitucional chileno en Covarrubias Cuevas, Ignacio, cit. (n. 76), pp. 411-433; EL MISMO, La desproporción de la proporcionalidad: aspectos problemáticos en su formulación y aplicación [en prensa en la Revista Chilena de Derecho].

${ }^{107}$ Representativo en esta línea es la opinión de dos profesores ZúñIga AÑAZco, Yanira, El principio de proporcionalidad como herramienta de racionalidad. Un análisis critico de su aplicación en la jurisprudencia del Tribunal Constitucional chileno, en Ius et 
La objeción de fondo estriba en que los bienes que muchos derechos manifiestan no son susceptibles de someterse a estándares que prestan utilidad en el ámbito técnico-cuantitativo antes que en la esfera del razonamiento de los bienes morales ${ }^{108}$. Lo que en estos casos se pretenden "medir" no son intereses ni cantidades sino cualidades morales de bienes humanos relevantes. Por eso es que en este contexto de aspectos inconmensurables del bienestar humano resulta tan contra-intuitivo el empleo de un método que parta y termine por utilizar un lenguaje de interés, costo, peso y balance antes que de lo que es jurídico, antijurídico, correcto o incorrecto ${ }^{109}$.

La segunda observación planteada en $i i$ ) dice relación con balancear, bajo un criterio utilitarista, derechos fundamentales inviolables u otros que sin serlo contienen aspectos medulares que son indisponibles frente a nociones utilitaristas o colectivistas del bien público. Dentro del primer grupo se encuentra la vida y el derecho a no ser torturado. En el segundo grupo mayoritario hay derechos que sin ser absolutamente inviolables -por lo que están sujetos a las restricciones que impone el bien común- igualmente contienen ciertas garantías que son indisponibles, a saber, la esfera más sensible del derecho a la intimidad o aspectos del derecho a un juicio justo. Para ilustrarlo con una pregunta: ¿deberían las garantías del debido proceso ser sacrificadas en pos del interés público prevaleciente en una situación de convulsión nacional?

Praxis, 16 (2010), p. 264; y Bordalí, Andrés - Zúñiga, Yanira, Análisis del fallo del Tribunal Constitucional sobre la píldora del día después, en Anuario de Derechos Humanos (Facultad de Derecho Universidad de Chile, 2010), p. 177. Ambos al comentar la sentencia "píldora del día después" (2008), y fundados en el test de proporcionalidad, critican que el Tribunal Constitucional debió haber ponderado "el costo de una incierta afectación de la vida del embrión versus el costo de una reducción de la eficacia de una politica de prevención del embarazo adolescente o de una intervención estatal para disminuir los efectos negativos del delito de violación", aunque no explican ni entregan los elementos acerca de cómo dicho trabajoso cálculo habría que llevarse a cabo.

${ }^{108}$ Webber, Gregoire C. N., Proportionality, Balancing, and the Cult of Constitutional Rights Scholarship, en Canadian Journal of Law and Jurisprudence, 23 (2010), p. 196.

${ }^{109}$ Finnis, John, Commensuration and Public Reason, en Ruth Chang editora, Incommensurability, Incompatibility, and Practical Reason (Massachusetts, Harvard University Press, 1997), p. 219, complementa la crítica afirmando que la conmensurabilidad es posible en el análisis de opciones alternativas en términos de costo- beneficio, es necesario que: $i$ ) los objetivos estén bien definidos; $i i)$ los costos puedan ser comparados teniendo como parámetro una única unidad de valor o medida (peso o moneda, por ejemplo); iii) los beneficios también puedan ser cuantificados de un modo que puedan ser medidos unos a otros; y $i v$ ) las diferencias entre los medios, que no consistan en los costos y beneficios comparables, y otros aspectos como la eficiencia de los mismos medios, no se estimen de relevancia. 
Así, lo que el CT pretende hacer (medir lo inmedible) no lo hace porque, a nuestro juicio, no puede hacerlo y, lo que efectivamente puede hacer (aplicar el test con los indispensables resguardos) tampoco lo hace, como veremos enseguida. El fenómeno denunciado no obsta a que en varias ocasiones en que aspectos indisponibles de la vida privada -los datos sensibles- han estado en juego, el Consejo ha puesto atajo a la tentación de efectuar un cálculo utilitarista, como el test de interés público en su versión de proporcionalidad en sentido estricto, que probablemente habría hecho sucumbir un aspecto medular de aquel derecho fundamental ante el altar de un derecho identificado con interés público.

Lo anterior es ciertamente destacable a la luz del deber del Consejo de "velarpor el adecuado cumplimiento de la ley $N^{\circ} 19.628$, de protección de datos de carácter personal"110 (artículo 33, letra m), aunque este resultado, como hemos dicho, no se haya logrado gracias a la proporcionalidad sino que a pesar de ella o bien conforme a nociones no consecuencialistas del aludido estándar, de modo que los datos sensibles de una persona no queden sujetos a un balanceo con el interés público o con otro derecho identificado con éste.

Se advierte así, que el test de interés público (aun aplicado en su integridad) seguirá siendo un escollo al mandato del Consejo de procurar satisfacer el interés público de la transparencia con el debido resguardo de los derechos que, según la Carta Fundamental, constituyen un límite al primero, a no ser que dicho criterio sea concebido y aplicado bajo una formulación que -en clave constitucional y legal- permita conciliar la promoción del bien común con el respeto a los derechos fundamentales sin que éstos queden expuestos a un sacrificio incontrarrestable a favor del aquél. Acerca de los presupuestos de esta noción y su modus operandi nos referiremos a continuación.

\section{El principio de divisibilidad como medio legitimador y morigerador del} test, que concilia la exigencia constitucional de promover el bien común con el pleno respeto a los derechos fundamentales.

Ya hemos expuesto las falencias que en términos de procedencia, uso, desuso y abuso afectan al test de interés público, particularmente en su versión de la regla de proporcionalidad en sentido estricto. El principio de divisibilidad (artículo 11, letra e $)^{111}$, aparte de encontrarse expresamente consagrado en la "Ley de transparencia" - por lo que no le pesan las objeciones de legitimidad

${ }^{110}$ La Ley No 20.285, artículo 33, letra j), también impone al Consejo el deber de "Velar por la debida reserva de los datos e informaciones que conforme a la Constitución y a la ley tengan carácter secreto o reservado".

${ }^{111}$ Ibíd., artículo 11, letra e), principio "conforme al cual si un acto administrativo contiene información que puede ser conocida e información que debe denegarse en virtud de causa legal, se dará acceso a la primera y no a la segunda". 
que perjudican al test de interés público- tampoco contiene en su formulación los riesgos que se han observado respecto de la noción y empleo del cuestionado test. De este modo, junto con acotar las desventajas que posee la proporcionalidad en sentido estricto, el instrumento propuesto presenta la ventaja inconmensurable de contribuir a la satisfacción del interés público, mediante el ejercicio del derecho de acceso, de un modo tal que admita la limitación de los derechos -en concreto, la vida privada- en pos de dicha finalidad pública, a condición que se respete la cobertura íntima del derecho intervenido -en este caso, los datos sensibles, armonizando de este modo el bien común con el respeto a los derechos fundamentales.

El deber de conciliar la promoción del bien común con el pleno respeto a los derechos de las personas no es una declaración lírica ni romántica sino un mandato constitucional y, el principio de divisibilidad (en adelante, también "la divisibilidad") es una herramienta prevista por el legislador cuya adecuada aplicación permite satisfacer las finalidades de la Ley $\mathrm{N}^{\circ} 20.285$-transparencia pública y respeto por los derechos de las personas, además de otros bienes públicos-cumpliendo paralelamente con la aludida exigencia constitucional sobre cuyos presupuestos sustantivos ${ }^{112}$ nos referiremos ahora.

Admitida aquella necesaria libertad de configuración de que han de gozar los órganos legislativo y ejecutivo para diseñar, formular, aprobar y ejecutar todas aquellas potestades que estimen pertinentes para la satisfacción de las necesidades públicas adoptadas conforme a su ideario, es que la Carta Fundamental ha previsto que la autoridad política pueda cumplir con los objetivos planteados a la ciudadanía en su programa de gobierno, a condición de que se respeten ciertos parámetros básicos contenidos en la Ley Fundamental.

a) Criterios constitucionales sustantivos que sustentan la definición y ejecución de políticas públicas o bienes de relevancia constitucional. El primer estándar sustantivo fluye con soltura del texto como del telos constitucional en cuanto prescribe que las potestades públicas no persiguen una finalidad distinta que la de promover el bien común de la sociedad ${ }^{113}$. Al ser la gran finalidad del Estado, cualquier otro

${ }^{112}$ Véase: Covarrubias Cuevas, I., cit. (n. 76), pp. 398-405, donde se desarrollan con mayor laxitud los supuestos de esta formulación.

${ }^{113}$ Artículo 1, inciso $4^{\circ}$ C.Pol.: "El Estado está al servicio de la persona humana y su finalidad es promover el bien común, para lo cual debe contribuir a crear las condiciones sociales que permitan a todos y a cada uno de los integrantes de la comunidad nacional su mayor realización espiritual y material posible [...]", complementado por la Ley № 18.575, artículo 3, inciso $1^{\circ}$, que prescribe que es deber de la Administración del Estado de atender "las necesidades públicas en forma continua y permanente". Esta misma disposición añade, asimismo, las siguientes finalidades de la Administración: fomentar " $e l$ desarrollo del pais a través del ejercicio de las atribuciones que le confiere la Constitución y la ley, y de la aprobación, ejecución y control de políticas, planes, programas y acciones de 
objetivo de política pública es secundario respecto de él, por lo que ha de quedar subordinado a su satisfacción. No obstante la generalidad y abstracción de estas normas constitucionales, su cumplimiento posee implicancias concretas y de relevancia ${ }^{114}$.

La segunda condición material exige que la búsqueda y obtención de la finalidad de política pública se haga con observancia al contenido de los derechos fundamentales reconocidos. Así lo dispone la Carta al expresar que el bien común ha de ser promovido "con pleno respeto a los derechos y garantías que esta Constitución establece". Esta definición constitucional es crucial toda vez que sostiene que la satisfacción del interés público supone como conditio sine qua non el "pleno respeto" a los derechos de las personas. Sin embargo, el alcance de esta disposición queda en entredicho si no se comprende al tenor de lo dispuesto por la siguiente exigencia material establecida por la Ley Fundamental.

El tercer criterio sustantivo previsto por el texto fundamental establece que los derechos fundamentales sometidos a regulación o limitación, en los casos que la Constitución lo autoriza, "no podrán afectar los derechos en su esencia, ni imponer condiciones, tributos o requisitos que impidan su libre ejercicio"115. Este parámetro es crucial, ya que junto con brindar una interpretación de contexto que es coherente con las exigencias precedentes, permite conciliar in abstracto dos objetivos que con habitualidad aparecen como contrapuestos o, al menos, tensionados entre sí: la satisfacción de políticas públicas regulatorias o de intervención y el pleno respeto a los derechos fundamentales. Una comprensión sistemática, unitaria y finalista de la Carta Fundamental conduce a una conclusión más bien armónica acerca de la referida tensión.

b) El contenido esencial de los derechos fundamentales como punto de encuentro entre las políticas públicas y el respeto a aquéllos. Si la promoción del bien común supone el "pleno

alcance nacional, regional y comunal", pero siempre subordinadas a la promoción del bien común.

${ }^{114}$ Una de las referidas implicancias derivan de la comprensión de lo siguiente: si la autoridad pública no puede sino buscar la satisfacción del bien común y la promoción de éste supone el respeto a los derechos fundamentales, entonces la revisión jurisdiccional sobre las decisiones regulatorias en las distintas actividades - no únicamente las de índole económica- no puede consistir en un escrutinio meramente formal por la simple razón de que aquello que es objeto del control no posee un contenido solo formal sino también sustantivo.

${ }^{115}$ Artículo $19 \mathrm{~N}^{\circ} 26$ C.Pol.: "La seguridad de que los preceptos legales que por mandato de la Constitución regulen o complementen las garantías que ésta establece o que las limiten en los casos en que ella lo autoriza, no podrán afectar los derechos en su esencia, ni imponer condiciones, tributos o requisitos que impidan su libre ejercicio". 
respeto" a los derechos fundamentales, esto supone la ausencia de restricciones al ejercicio de éstos. Previo a responder negativamente la interrogante formulada es necesario presupuestar lo siguiente. En primer lugar, que es efectivo que el texto constitucional es inequívoco en afirmar que no es posible satisfacer el bien común vulnerando los derechos de las personas. En este sentido, el gran desafío que la Constitución Política plantea al derecho regulatorio consiste en armonizar los intereses públicos con los de los particulares y, si esto no es posible, hacer prevalecer el bien común respetando, en todo caso, los derechos fundamentales.

El segundo presupuesto, como se ha visto, que emana literalmente del artículo $19 \mathrm{~N}^{\circ} 26$ C.Pol., expresa que los derechos fundamentales no pueden ser regulados o desarrollados de un modo que se impida su libre ejercicio o se afecte su contenido esencial. Lo destacable es que esta garantía admite que los derechos pueden ser objeto de condiciones, requisitos o cargas en el entendido que éstas no terminen por sacrificar los derechos sujetos a dichas regulaciones. Esta formulación, admisible en el texto y contexto de la Ley Fundamental, también hace posible que se compatibilice la finalidad histórica de los textos constitucionales -la contención del poder por los derechos-con la finalidad actual de la Constitución chilena: la promoción del bien común, no sólo por el Estado, sino por toda la sociedad.

Si el poder público puede legítimamente limitar el ejercicio de los derechos ¿cómo diantres se cumple con el objeto de que éstos operen como límites a aquél? Entendiendo que la condición que la Constitución exige para promover el bien común es el respeto al contenido esencial los derechos de las personas. De este modo, si bien la Carta Fundamental reconoce que estos derechos deben someterse a las políticas públicas regulatorias que persigan el interés público, como contrapartida, dichas potestades de intervención o gravamen no podrán -so pretexto de regular- llegar al punto de sacrificar parcial o totalmente los derechos afectados en nombre del referido bien común.

La referida formulación es la que, a nuestro juicio, mejor compatibiliza la satisfacción del bien común con la intangibilidad de la esencia de los derechos fundamentales, reconociéndole a la autoridad la indispensable libertad para buscar el mejor modo de satisfacer las necesidades públicas, a condición de que no se pase por sobre el contenido esencialmente protegido por los derechos sujetos a intervención. De este modo, la regulación al ejercicio de los derechos es legítima siempre que las restricciones a éstos (a) se encuentren debidamente justificadas en la búsqueda del interés público (artículo $1^{\circ}$ inciso 4) y, en caso alguno, (b) importen la privación del derecho o le impongan "condiciones, tributos o requisitos que impidan su libre ejercicio" (artículo 19 $\mathrm{N}^{\circ} 26$ C.Pol.). 
En fin, el respeto al contenido medular de los derechos constituye una condición sine qua non del respeto al bien común, toda vez que éste no puede satisfacerse sacrificando o impidiendo el ejercicio de las referidas libertades. ¿Cómo es posible conciliar las indispensables restricciones que en ocasiones impone la vida en comunidad con los derechos fundamentales? Comprendiendo que el "pleno respeto a los derechos y garantias que esta Constitución establece" a que se refiere el artículo $1^{\circ}$, inciso 4 C.Pol., se traduce en un pleno y total respeto a los "derechos en su esencia", además de la prohibición constitucional de establecer regulaciones que impidan "su libre ejercicio", a que se refiere el artículo $19 \mathrm{~N}^{\circ} 26$ en relación con el inciso segundo del artículo 5 C.Pol. ${ }^{116}$.

\section{Los "datos sensibles" de una persona no quedan superados por balanceo} alguno con el interés público: el rol integrador del artículo $19 N^{\circ} 26$ de la Constitución.

Como se ha visto en algunos de los casos precedentemente revisados, el CT ha denegado solicitudes de acceso a la información pública -con o sin el empleo del "test de daño" o de interés público- en la medida que la información requerida versa sobre datos sensibles de terceros. Así, a modo ejemplar, ha resuelto denegar la información requerida atendida que "la publicidad [...] de la información contenida en la carta solicitada puede afectar derechos de terceros [...], en particular tratándose de la esfera de su vida privada, lo mismo que su derecho a la salud"117. De este modo, el CT admite la legitimidad y necesidad de imponer restricciones en el ejercicio del derecho a la intimidad con el fin de satisfacer el bien público de la transparencia de la función pública, dejando a salvo aquella información más sensible a resguardo de un predominio absoluto del referido fin constitucionalmente lícito.

Este resultado es destacable, como quiera que compatibiliza la satisfacción del bien común o de un aspecto de él (la transparencia pública) con los derechos de las personas entendiendo que éstos deben siempre aceptar las indispensables reducciones y limitaciones en la esfera protegida de sus derechos a condición de que ellos no terminen sacrificados del todo en nombre de un interés público prevaleciente. Este es un modo adecuado de entender, como señalamos en el acápite precedente, que no hay oposición irreductible,

${ }^{116}$ Artículo $5^{\circ}$, inciso $2^{\circ}$ C.Pol.: “El ejercicio de la soberanía reconoce como limitación el respeto a los derechos esenciales que emanan de la naturaleza humana. Es deber de los órganos del Estado respetar y promover tales derechos, garantizados por esta Constitución, así como por los tratados internacionales ratificados por Chile y que se encuentren vigentes".

${ }^{117}$ CT, Decisión C335-10, Ibíd., c. 6. Otros decisiones análogas: A53-09, c. 11 y C198-10, c. 9, a modo ejemplar. 
sino que complementariedad, entre la búsqueda del bien común y el respeto a los derechos fundamentales, tal como lo exige una interpretación armónica del artículo $1^{\circ}$ inciso cuarto y las garantías contenidas en el artículo $19 \mathrm{~N}^{\circ}$ 26C.Pol. ${ }^{118}$.

El marco previamente expuesto no constituye sino una lectura desarrollada en clave constitucional para contribuir a brindar un mayor sustento normativo a lo obrado por el CT en este aspecto y que debe ser destacado. En tal sentido, es posible adelantar la siguiente formulación sobre lo resuelto por el Consejo aunque ella no haya sido explícitamente reconocida por este organismo: si el derecho a la intimidad admite diversas gradaciones para los efectos de la Ley No 16.628 sobre: Protección de datos de carácter personal, correspondiendo los datos sensibles a la esfera más íntima, es este núcleo del derecho fundamental a la vida privada el que queda inmunizado frente a cualquier balance con el interés público, en virtud del artículo $19 \mathrm{~N}^{\circ} 26$ C.Pol.

Aplicado lo expuesto en el lenguaje del Consejo: si lo más sensible de la vida privada no puede quedar sacrificado frente a los criterios de interés público, esto es lo más parecido a sostener que el acceso a la información pública (como derecho) o la transparencia pública (como bien constitucionalmente reconocido) encuentran su limitación en el contenido esencial del derecho a la vida privada, esto es, en su manifestación de datos sensibles, según lo dispuesto por la garantía consagrada en el artículo $19 \mathrm{~N}^{\circ} 26$ C.Pol. ${ }^{119}$.

Así, en este específico punto, el CT, sin quizás advertirlo, efectúa una adecuada aplicación implícita de las indicadas disposiciones constitucionales. El artículo 1 inciso cuarto, que reconoce que el bien común ha de propenderse "con pleno respeto a los derechos y garantías que esta Constitución establece" y el $19 \mathrm{~N}^{\circ} 26^{120}$, que garantiza que las normas legales que regulen o limiten el

${ }^{118}$ Sobre los fundamentos políticos de una noción armónica entre bien común y derechos fundamentales, en una perspectiva comunitarista, se sugiere ver: PRADO Donoso, Maximiliano, Limitación de los derechos humanos. Algunas consideraciones teóricas, en Revista Chilena de Derecho, 34 (2007) 1, p. 77 ss.

${ }^{119}$ Ello puede desprenderse de CT, C711-10, “[...] Entregue a don E. S. C. una copia de la información relativa al nivel de experiencia [...] cuidando de tarjar todos aquellos datos personales y/o sensibles de contexto que contengan los documentos que conforman la oferta técnica, tanto del oferente como de terceros".

${ }^{120}$ CT, decisión C-722-10, voto disidente, c. 7: “[...] La información de carácter privado que los particulares están obligados a entregar a los órganos de la Administración no pierde esa naturaleza por el sólo hecho de que ésta obre en poder del Estado, pues ello equivaldría a asignarle a esa entrega la capacidad juridica de alterar la real naturaleza de la información, deviniendo ésta de privada en pública por un mero cambio en su tenedor $y$, adicionalmente, haciendo perder a los titulares de esa información privada el núcleo esen- 
ejercicio de los derechos "no podrán afectar los [...] en su esencia, ni imponer condiciones [...] que impidan su libre ejercicio".

De este modo ha de comprenderse adecuadamente que el "pleno respeto a los derechos", su límite infranqueable se juega en el respeto a su contenido esencial, que en el caso del derecho a la vida privada viene dado por los "datos sensibles" del derecho fundamental a la intimidad.

\section{Conclusiones}

1. La primera aproximación afirma que el test de interés público, de cuño utilitarista, concebido por el CT carece de sustento normativo en la "Ley de transparencia". No sólo el texto y contexto de la "Ley" prevé un modo de adjudicación distinto al de una ponderación balanceadora; además la historia fidedigna del establecimiento de dicho cuerpo legal conduce a la misma conclusión al haber sido rechazado en su trámite legislativo un inciso que autorizaba expresamente llevar adelante un análisis de balanceo optimizador.

Esta conclusión se ve favorecida cuando uno de los derechos en juego es la vida privada, toda vez que en dos ejemplos relevantes de leyes sobre acceso a la información, en el derecho comparado, el referido test está derechamente prohibido frente a la información de carácter personal (Inglaterra) o su empleo se encuentra condicionado a que la invasión en la vida privada no sea injustificado (Estados Unidos).

2. En segundo término, se ha constatado que el CT ha omitido aplicar el test de interés público al que ha proclamado con un carácter general en sus decisiones. No sólo no lo ha hecho operar conforme a las exigencias de dicho test -de proporcionalidad- sino que en ocasiones no lo ha aplicado en modo alguno.

Por el contrario, lo que con cierta habitualidad ha operado es sólo uno de los requisitos del aludido estándar -el principio de proporcionalidad en sentido estricto- cuya aplicación aislada de los restantes pasos del test es rechazada por quienes adhieren a esta modalidad de adjudicación constitucional y, particularmente, por los autores habitualmente citados por el Consejo.

3. El tercer aspecto abordado arranca del supuesto que la proporcionalidad en sentido estricto, tantas veces empleada por el CT, contribuye conceptualmente a allanar el camino a un balanceo entre el derecho de acceso a la información y el derecho a la vida privada en que el primero termine

cial de su derecho a la privacidad y propiedad, contraviniendo de esta forma la garantía que afirma el numeral 26 del artículo 19 de la Constitución". 
imponiéndose sin cuartel sobre el segundo. Tanto es así que en ocasiones en que el Consejo ha querido brindar un firme resguardo a los "datos sensibles", ha evitado emplear el referido test.

4. Esto evidencia no sólo que la proporcionalidad no sirve para todos los casos, sino que tampoco es razonable llevar adelante un balanceo de costo-beneficio cuando lo que se trata de ponderar son bienes o derechos, como la cobertura más íntima de la vida privada, que no son susceptibles de ser evaluados bajo un criterio exclusiva o primordialmente utilitarista. En tal sentido, difícilmente puede operar la proporcionalidad cuando lo que debe someterse a balanceo son aspectos inconmensurables e inviolables del bienestar humano.

5. Este modo de aproximación no encuentra sustento en la "Ley de transparencia" ni en la Constitución Politica. Carece de apoyo en la primera, toda vez que conforme a ésta, el Consejo debe compatibilizar la satisfacción del derecho de acceso a la información con el respeto a la información personal, mediante el principio de divisibilidad.

También carece de apoyo en la Carta Fundamental, pues el diseño constitucional es claro en admitir que los derechos pueden quedar sujetos a las exigencias que el bien común impone, a condición que estas injerencias no afecten el contenido esencial del derecho intervenido ni hagan imposible su ejercicio.

6. Finalmente se sugiere complementar la fundamentación normativa que contribuya a dar un mayor sustento a la destacable labor del Consejo de no dejar a los "datos sensibles" - la esfera más íntima de la vida privada- a merced de un balanceo utilitarista con la transparencia pública mediante el ejercicio del derecho de acceso a la información.

7. En fin, y a modo de conclusión general, creemos que el Consejo ha de reforzar el sustrato constitucional del principio de divisibilidad, que junto con no padecer de las falencias que presenta el test de interés público, es un instrumento que adecuadamente aplicado permite satisfacer la transparencia de la función pública con el pleno respeto al contenido medular o sensible de los derechos fundamentales, que limitan, en este caso absolutamente, el ejercicio del derecho de acceso.

\section{BiBLIOgRAFÍA}

Aldunate Lizana, Eduardo, Aproximación conceptualy critica al neoconstitucionalismo, en Revista de Derecho de la Universidad Austral de Chile, 23 (2010) 1.

AlEXY, Robert, Epílogo a la Teoría de los derechos fundamentales (traducción de Carlos Bernal Pulido), en REDC., 66 (2002). 
AleXY, Robert, Teoria de los derechos fundamentales (Traducción de Ernesto Garzón Valdés, Centro de Estudios Políticos y Constitucionales, Madrid, 1997), 610 pp.

BARNES, Javier, El principio de proporcionalidad. Estudio preliminar, en Cuadernos de Derecho Público, 5 (1998).

BARNES, Javier, Introducción al principio de proporcionalidad en el Derecho comparado y comunitario, en Revista de Administración Pública, 135 (1994).

Bernal Pulido, Carlos, El principio de proporcionalidad y los derechos fundamentales (Madrid, Centro de Estudios Políticos y Constitucionales, 2003), 871 pp.

Bordalí, Andrés - ZúÑIga, Yanira, Análisis del fallo del Tribunal Constitucional sobre la píldora del día después, en Anuario de Derechos Humanos (Facultad de Derecho Universidad de Chile, 2010).

BROOKE, Heather, Your Right to Know. How to Use the Freedom of Information Act and Other Access Laws (London, Pluto Press, 2005), 309 pp.

CAMAcho CePeda, Gladys, La delimitación de la noción de información pública y la jurisprudencia del Consejo para la Transparencia, en Gaceta Juridica, 375 (2011).

CleRICO, Laura, El examen de proporcionalidad: entre el exceso por acción y la insuficiencia por omisión o defecto, ahora, en CARBONELL, Miguel (coordinador), El principio de proporcionalidad en la interpretación jurídica (Santiago, Librotecnia, 2010).

Contreras VÁs Quez, Pablo, Poder privado y derechos. Eficacia horizontaly ponderación de los derechos fundamentales (Santiago, Ediciones Universidad Alberto Hurtado, 2009), 214 pp.

CovarRubias Cuevas Ignacio, La desproporción de la proporcionalidad: aspectosproblemáticos en su formulación y aplicación [en prensa en Revista Chilena de Derecho].

Covarrubias Cuevas, Ignacio, El bien común, el interés público o los fines constitucionalmente legitimos como justificaciones del regulador para limitar los derechos fundamentales, ahora, en ARANCIBIA - MARTínez - Romero (coordinadores) Litigación pública (Santiago, Abeledo Perrot - Thomson Reuters, 2011).

DíAz GARCÍA, L. Iván, Aplicación del principio deproporcionalidad en orden a juzgar sobre la licitud o ilicitud de una restricción a derechos fundamentales, en Revista de Derecho de la Pontificia Universidad Católica de Valparaíso, 36 (2011, semestre $\left.1^{\circ}\right)$.

Finnis, John, Commensuration and Public Reason, en Ruth Chang (editora), Incommensurability, Incompatibility and Practical Reason (Massachusetts, Harvard University Press, 1997), 384 pp.

García Pino, Gonzalo - Contreras VÁsquez., Pablo, Derecho de acceso a la información en Chile: nueva regulación e implicancias para el sector de la Defensa Nacional, en Estudios Constitucionales, 7 (2009).

Grimm, Dieter, Proportionality in Canadian and German Constitutional Law Jurisprudence, en University of Toronto Law Journal, 57 (2007).

Halstuk, Martin, Blurred Vision: The Supreme Court's FOIA Opinions on Invasion of Privacy, en Davis, C. N. - Splichal, Sigman (editores), Acces Denied. Freedom of Information in the Information Age (Iowa, Iowa State University Press, 2000).

Kumm, Mattias, The Idea of Socratic Contestation and the Right to Justification: The Point of Rights Based Proportionality Review, en Law \& Ethics Human Rights, 4 (2010).

López-Ayllón, Sergio - Posada, Alejandro, Las pruebas de daño e interés público en materia de acceso a la información pública. Una perspectiva comparada, en Derecho Comparado de la Información, 9 (2007) [disponible en: http://www.juridicas.unam. $\mathrm{mx} / \mathrm{publica} / \mathrm{rev} / \mathrm{decoin} / \mathrm{cont} / 6 / \mathrm{art} / \mathrm{art} 5 . \mathrm{htm}]$.

Nogueira AlCalá, Humberto, El principio de proporcionalidad y su aplicación en 
Sudamérica por la jurisdicción constitucional, con especial mención al Tribunal Constitucional chileno, en CARBONELl, Miguel, (coordinador), El principio de proporcionalidad en la interpretación jurídica (Santiago, Librotecnia, 2010).

Prado Donoso, Maximiliano, Limitación de los derechos humanos. Algunas consideraciones teóricas, en Revista Chilena de Derecho, 34 (2007) 1.

Rajevic Mosler, Enrique, La jurisprudencia inicial del Consejo para la Transparencia, en Revista de Derecho del Consejo de Defensa del Estado, 22 (2009).

Rivers, Julian, Proportionality and Variable Intensity of Review, en Cambridge Law Journal, 65 (2006).

Stone, Alec / Mathews, Jud, Proportionality Balancing and Global Constitutionalism, en Columbia Journal of Transnational Law, 47 (2009).

Tello, C. - Cerna, M. - Pavón, A., Acceso a la información pública: los desafíos del Consejo de la Transparencia, en Anuario de Derechos Humanos (2009 [2010]).

Webber, Gregoire C. N., Proportionality, Balancing, and the Cult of Constitutional Rights Scholarship, en Canadian Journal of Law and Jurisprudence, 23 (2010).

Zúñiga AÑazco, Yanira, El principio de proporcionalidad como herramienta de racionalidad. Un análisis crítico de su aplicación en la jurisprudencia del Tribunal Constitucional chileno, en Ius et Praxis, 16 (2010). 
